\title{
Modeling and Analysis of the Material Removal Rate for Ultrasonic Vibration-assisted Polishing of Optical Glass BK7
}

\section{Yingdong Liang}

School of Mechanical Engineering and Automation, Northeastern University, NO. 3-11, Wenhua Road, Heping District, Shenyang 110819, People's Republic of China

\section{Chao Zhang}

School of Mechanical Engineering and Automation, Northeastern University, NO. 3-11, Wenhua Road, Heping District, Shenyang 110819, People's Republic of China

\section{Xin Chen}

School of Mechanical Engineering and Automation, Northeastern University, NO. 3-11, Wenhua Road, Heping District, Shenyang 110819, People's Republic of China

\section{Tianqi Zhang}

School of Mechanical Engineering and Automation, Northeastern University, NO. 3-11, Wenhua Road, Heping District, Shenyang 110819, People's Republic of China

Tianbiao Yu ( $\nabla$ tianbiaoyudyx@gmail.com )

Northeastern University https://orcid.org/0000-0002-6161-8838

\section{Ji Zhao}

School of Mechanical Engineering and Automation, Northeastern University, NO. 3-11, Wenhua Road, Heping District, Shenyang 110819, People's Republic of China

\section{Research Article}

Keywords: Ultrasonic vibration-assisted polishing, Ultrasonic atomization, Material-removal rate, Trajectory simulation, optical glass (BK7)

Posted Date: March 17th, 2021

DOl: https://doi.org/10.21203/rs.3.rs-307215/v1

License: (c) (i) This work is licensed under a Creative Commons Attribution 4.0 International License. Read Full License

Version of Record: A version of this preprint was published at The International Journal of Advanced Manufacturing Technology on September 7th, 2021. See the published version at 
https://doi.org/10.1007/s00170-021-07967-7. 


\title{
Modeling and analysis of the material removal rate for
}

\section{ultrasonic vibration-assisted polishing of optical glass BK7}

Yingdong Liang ${ }^{1}$, Chao Zhang ${ }^{1}$, Xin Chen ${ }^{1}$, Tianqi Zhang ${ }^{1}$, Tianbiao Yu ${ }^{1}$, Ji zhao ${ }^{1}$, corresponding author: Tianbiao Yu tianbiaoyudyx@gmail.com

School of Mechanical Engineering and Automation, Northeastern University, NO. 3-11, Wenhua Road, Heping District, Shenyang 110819, People's Republic of China

Keywords: Ultrasonic vibration-assisted polishing; Ultrasonic atomization;

Material-removal rate; Trajectory simulation; optical glass (BK7);

\begin{abstract}
The emergence of ultrasonic vibration-assisted polishing technology has effectively improved the machining accuracy and efficiency of hard and brittle materials in modern optical industry, however, the material removal mechanism of ultrasonic vibration-assisted polishing (UVAP) still needs to be further revealed. This paper focuses on the material removal mechanism of ultrasonic vibration-assisted polishing of optical glass (BK7), the application of ultrasonic vibration to axial vibration and the atomization of polishing slurry, the material removal model was established. Based on the analysis of the relationship between the nominal distance $d$ of the polishing pad and the actual contact area distribution, the prediction of the material removal profile is realized. In addition, the effects of different parameters on the material removal rate (MRR) were analyzed, including polishing force, spindle speed, abrasive particle size, ultrasonic amplitude, feed rate, and flow-rate of polishing slurry. Based on the motion equation of abrasive particles, the trajectory of abrasive particles in the polishing slurry was simulated, and the simulation results show that the introduction of the ultrasonic vibration field changes the motion state and trajectory of embedded and free abrasive particles. The new model can not only qualitatively analyze the influence of different process parameters on MRR, but also predict the material removal depth and MRR, providing a possibility for deterministic material removal and a theoretical basis for subsequent polishing of complex curved surfaces of optical glass.
\end{abstract}

\section{Introduction}

Optical glass (BK7) is widely used in optoelectronics, diffractive optical elements, biomedicine and other fields because of its excellent mechanical properties 
and chemical stability [1]. Therefore, the demand for this material is increasing, and the requirement of precision is higher and higher. However, due to its high hardness and brittleness, it is difficult to obtain high precision machined surface with conventional machining methods [2]. Scholars have studied processing methods including UVAP, jet polishing [3,4], laser polishing [5] and magnetorheological polishing [6], etc. Among these technologies, UVAP can greatly reduce the limitation of hard and brittle materials on machining, and the introduction of ultrasonic can make the abrasive particles homogeneous and decrease clustering phenomenon, effectively improve the trajectory of abrasive particles, phenomenon, which can improve machining efficiency and accelerate the removal of subsurface damage, which has attracted more and more attention and research of scholars [7].

Polishing is an essential process for precision and ultra-precision machining, the quality of workpiece is affected by the quality of polishing directly. Based on Preston equation [8], many experiments and simulations have been done on the mechanism of conventional polishing. Zhang et al [9] modeled the mechanics of contact and friction mechanisms during polishing, then obtained the contact state, load distribution and spatial polishing trajectory of the contact surface in the polishing process through the finite element simulation analysis of the small spherical optical lens. Lin et al [10] obtained the pressure distribution in the polishing process by finite element simulation, and proposed a model to describe the relationship between polishing parameters and MRR based on the simulation results. Zhang et al [11,12] studied the material removal of fixed abrasive polishing in detail. A material removal model considering the wear law of polishing tools based on Hertz contact theory was proposed, which suggested that the material removal profile is related to the surface geometry and mechanical properties of the polishing tools and polishing conditions. Wang [13] develop a prediction model of material removal depth of the workpiece surface, and present an approach to achieve the material removal profile, which considered the influence of abrasive size, established a linear removal intensity model according to material removal amount, and the material removal depth was calculated by integrating the contact path. Zhong [14] conducted in-depth research on the chemical mechanical polishing (CMP) of optical silicon substrates, using two-body abrasion CMP to replace the traditional three body abrasion. Comparative experiments show that the MRR is largely dependent on head load and table speed would give the same effect, which can greatly improve the MRR efficiency. Fan [15] analyzed the influence of various process parameters (normal force, angular spindle velocity, angular feed rate, abrasive particle size, polishing slurry properties, polishing pad morphology parameters and tool path curvature) on material removal, defined the removal depth per unit length of polishing path as the material removal index, and calculated the material removal profile model through the material removal index along the tool path.

Conventional polishing methods for hard and brittle materials with long processing cycles, low efficiency, and unsustainable surface quality have gradually failed to meet modern industrial requirements. In recent years, ultrasonic vibration has been introduced into the polishing, which can improve the polishing quality and 
efficiency for hard and brittle materials. Ultrasonic machining was first proposed by G August, s Roland [16] in 1927, and was applied to actual machining in 1920s. In recent decades, scholars have done a lot of research on UVAP. Sanjay Agarwal [17] analyze the material removal mechanism and removal rate of UVAP of glass with a mild steel tool using boron carbide abrasive in water as slurry. The propagation and intersection of radial and median cracks that are induced due to repeated impacts of abrasive particles, which will lead to material removal. The models of shocking force and MRR are derived, which take into account the elastic properties and non-uniformity of abrasive particles, and the mechanical properties of workpiece and abrasive particle Zhang [18] considered the lateral extension of the contact area, the periodic changes of polishing force and contact radius, modeled the local surface profile and material removal distribution function of UVAP, and obtained that larger axial ultrasonic amplitude can improve the Preston coefficient through experiments. The model has good prediction results for local surface profile, maximum contact radius, material removal depth and MRR. Han [19] fixed the workpiece on a rectangle hexahedron ultrasonic sonotrode platform with optimized slots platform to realize the assisted ultrasonic vibration of workpiece, and carried out experimental research on austenitic stainless steel materials. It is concluded that the transverse ultrasonic vibration applied to the workpiece can reduce polishing force, improve machining accuracy, and enhance the proportion of plastic shear effect in material removal. When the vibration direction of the workpiece is consistent with the polishing path direction, the polishing force distribution is more uniform and the surface roughness is lower. When the included angle is $45^{\circ}$, the average polishing force can be reduced by $75.2 \%$. Wang [20] studied the mechanism of ultrasonic vibration assisted grinding (UAG) of hard and brittle materials, established the mathematical model of UAG of brittle materials, conducted in-depth research on the influence of input variables on grinding force and prediction of surface roughness, and obtained the advantages of UAG through theoretical analysis and experimental verification.

In addition to the above studies of UVAP, ultrasonic has also been used for the ultrasonic atomization of polishing slurry. Ultrasonic atomization can produce droplets less than $100 \mathrm{~nm}$, which have small temperature change [21]. Zhang [22] analyzed the effects of operating ultrasonic parameters such as input power and flow rate, and concluded that equipment parameters and liquid physicochemical properties have a great relationship with the mean particle size and particle size distribution of droplets. An effective ultrasonic atomization method was obtained through optimizing the parameters, and the ultrasonic atomization mechanism was established. Kazuhiko Sekiguchi [23] determined the relation between the ultrasonic frequency and the size distribution of the droplets, proposed the generation mechanism of ultrasonic atomization, and concluded that ultrasonic frequency has a negative correlation with atomized droplet diameter of atomized droplet, and is positively correlated with the number and concentration. It is considered that the atomized droplet diameter can be controlled by controlling ultrasonic frequency, power intensity and density of ultrasonic energy transducer.

In conclusion, ultrasonic vibration-assisted polishing is proved to be an effective 
method for machining hard and brittle materials. However, the theory of ultrasonic vibration-assisted polishing of optical glass is still rarely studied, and the mechanism has not been fully explained so far. Therefore, this paper focuses on the mechanism of ultrasonic vibration-assisted polishing of optical glass (BK7), a predict model of the MRR based on ultrasonic atomization is proposed. The motion of abrasive particles of UVAP was discussed to understand the complexity polishing process. The actual contact area between the polishing pad and the workpiece and its influence on the polishing accuracy are analyzed. At the same time, the influence of different process parameters on the MRR is analyzed, including not only the process parameters, which refer to the polishing force, spindle speed and feed rate, but also the abrasive particle size, as well as ultrasonic amplitude and flow-rate of polishing slurry. This study can provide a theoretical basis for complex surfaces with UVAP.

\section{Material removal rate model of the optical glass}

\subsection{Motion analysis of ultrasonic vibration}

In this study, the cylindrical polishing tool is used to polish the optical glass (BK7). The polishing tool will leave a circular material removal area on the workpiece to be processed. In the polishing process, if the load is constant, the contact area is also constant[15]. Because the polishing head is directly driven by the ultrasonic electric spindle, the equation of motion of the polishing head is:

$$
\begin{aligned}
& z=z_{0}+A \sin (2 \pi f t) \\
& v(t)=2 \pi f A \cos (2 \pi f t) \\
& a(t)=-4 \pi^{2} f^{2} A \sin (2 \pi f t)
\end{aligned}
$$

where, $z_{0}$ is initial position of polishing head, $f$ and $A$ is ultrasonic frequency and ultrasonic amplitude, respectively.

\subsection{Contact between the polishing pad and workpiece surface}

It is known that the polishing pad surface is much rougher than the workpiece surface, so when microscopic analysis is performed, the workpiece surface is often simplified to a flat surface and the polishing pad surface is considered as a rough surface, as shown in Figure 1. When the polishing pad touches the workpiece surface under a constant load, the distance between the reference surface and the workpiece surface is the nominal distance (d). The polishing pad microscopic surface is randomly distributed, so a Gaussian distribution is used to describe the polishing pad microscopic surface height distribution [23], as shown in Eq (2). 
$\varphi(h)=\frac{1}{\sigma \sqrt{2 \pi}} \exp \left(-\frac{h^{2}}{2 \sigma^{2}}\right)$

where, $\mathrm{h}$ is the average distance between polishing pad and workpiece, $\sigma$ is standard deviation of polishing pad surface height distribution, and $\sigma=\sqrt{\frac{\pi}{2}} R_{a}$.

The actual contact area between the polishing pad and the workpiece is given by $A=\int_{d}^{\infty} \eta A_{0} \pi R_{0}(h-d) \varphi(h) d h$

Where, $\eta$ is the convexity density, $A_{0}$ is the apparent area and $R_{0}$ is the average convexity radius. The pressure between pad and workpiece is

$$
P=\int_{d}^{\infty} f \cdot N_{t} \cdot \varphi(h) d h=\frac{4}{3} N_{t} \sqrt{R_{0} E_{p w}} \int_{d}^{\infty}(h-d)^{\frac{3}{2}} \varphi(h) d h
$$

where, $f$ is stress of single convex peak, $N_{t}$ is the total number of abrasive particles involved in polishing. $E_{p w}$ is the contact modulus of the workpiece and the polishing pad given by $1 / E_{p w}=\left(1-v_{p}^{2}\right) / E_{p}+\left(1-v_{w}^{2}\right) / E_{w}$. Thus, if the polishing pressure $\mathrm{P}$ is known, the nominal distance $\mathrm{d}$ can be calculated from Eq. (4).

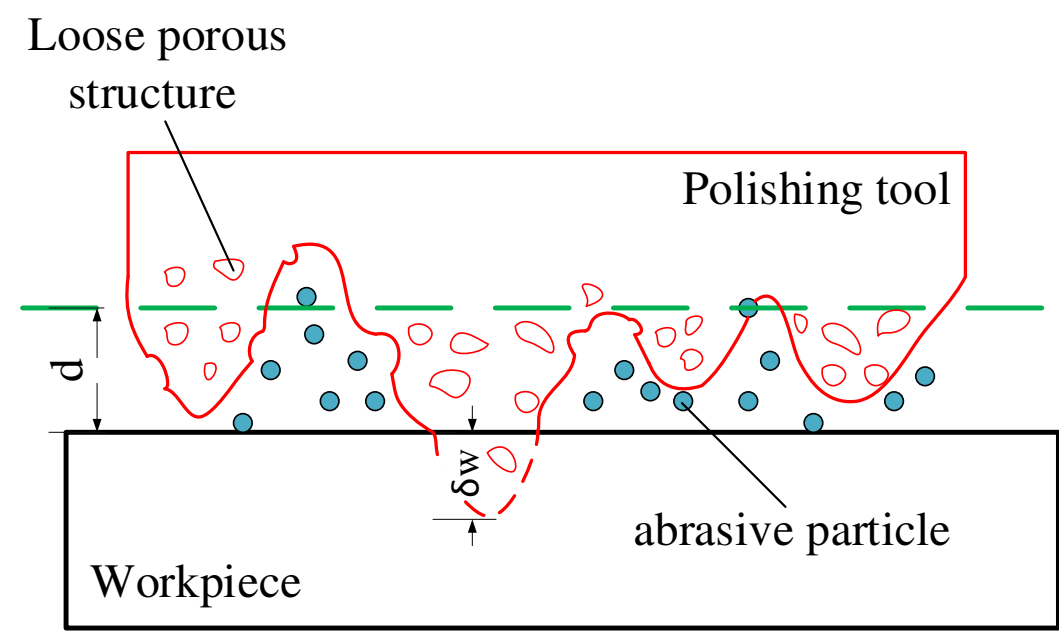

Fig. 1. Interactions between polishing tool, abrasive particle and workpiece.

\subsection{Total number of abrasive particles involved in polishing}

In the UVAP, not all the abrasive particles distributed in the polishing liquid participate in the polishing process, and the abrasive particles participating in the polishing are called effective abrasive particles. In this paper, polishing fluid is sprayed by ultrasonic peristaltic pump[16], a calculation method of effective abrasive particles based on ultrasonic atomization is proposed. If $\varepsilon$ is the utilization rate of 
effective abrasive particles and $N$ is the total number of abrasive particles ejected by the slurry atomizing nozzle, the effective abrasive number $N_{e}$ can be expressed as:

$N_{e}=N \varepsilon$

It is known that the mass of a single abrasive is $m=\frac{4}{3} \rho_{m} \pi r^{3}, Q$ is the flow rate per unit cycle, $\rho_{y}$ is the density of polishing liquid, $C_{m}$ is the percentage concentration of polishing liquid, $M$ is the total mass of abrasive particles, and $V_{m}$ is the volume of the polishing fluid that flows out of the nozzle within a cycle. In summary, the total mass of abrasive particles can be expressed as

$M=\rho_{y} V_{m} C_{m}=\rho_{y} Q T C_{m}$

So, the total number of abrasive particles is:

$N_{t}=\frac{M}{m}=\frac{3 \rho_{y} Q T C_{m}}{4 \rho_{m} \pi r^{3}}$

Assuming that the ratio of micro convex peaks on the surface of polishing head is $\phi$, the effective number of abrasive particles $N_{s}$ participating in the polishing process is:

$N_{s}=\phi \cdot N_{t}=\frac{3 \rho_{y} Q T C_{m} \phi \varepsilon(t)}{4 \rho_{m} \pi r^{3}}$

\subsection{Relative sliding speed of abrasive particles}

As shown in Fig 2, for any point $M(x, y)$ on the polishing path, the speed $V_{r}$ generated by the rotation of the polishing tool can be expressed as:

$\mathrm{V}_{\mathrm{r}}=\omega_{p} \sqrt{x^{2}+y^{2}}$

where, $\omega_{p}$ is spindle speed. When the feed speed of polishing tool is $\mathrm{V}_{j}$, the relative sliding speed of abrasive particles is:

$\mathrm{V}_{\mathrm{s}}=\sqrt{\mathrm{V}_{\mathrm{r}}^{2}+\mathrm{V}_{\mathrm{j}}^{2}-2 \mathrm{~V}_{\mathrm{r}} \mathrm{V}_{\mathrm{j}} \cos (\pi-\theta)}$

and, $\cos \theta=\frac{x}{\sqrt{x^{2}+y^{2}}}$ 


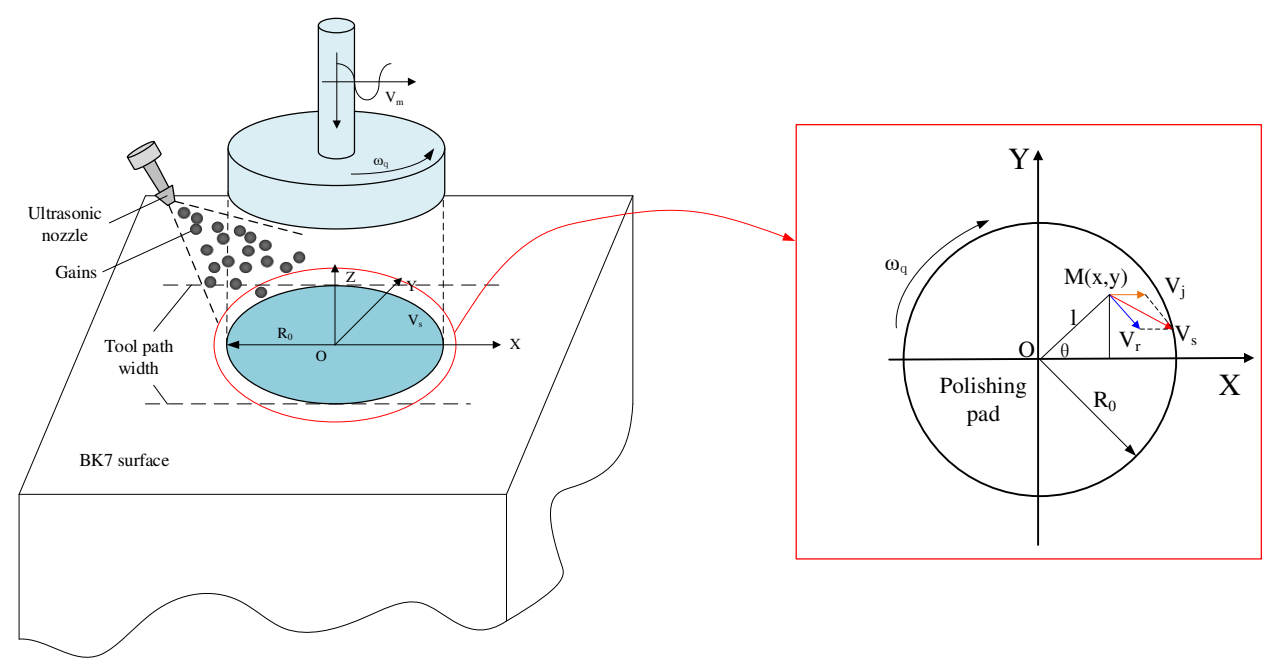

Fig. 2 Schematic diagram of relative velocity

\subsection{The material removal of a single abrasive particle}

The ultrasonic polishing process can be abstracted as a large number of abrasive particles high-frequency impact on brittle material surface. As shown in the Fig 3, based on the indentation fracture model [17], when the abrasive particles impact the workpiece, radial cracks appear on the surface of the workpiece, and transverse cracks appear when the abrasive particles are separated from the workpiece. Assuming that only the broken volume of the abrasive particles is considered in the ultrasonic polishing period, the material removal is determined by the length of the transverse cracks and the depth of the longitudinal cracks. In the ultrasonic vibration period, the material removal amount is approximately equal to the elliptic cone volume shown in Fig. 3, which is the sum of the crushing volumes from the point when the abrasive particles directly contact the workpiece to the point when the abrasive particles just leave the workpiece [20].

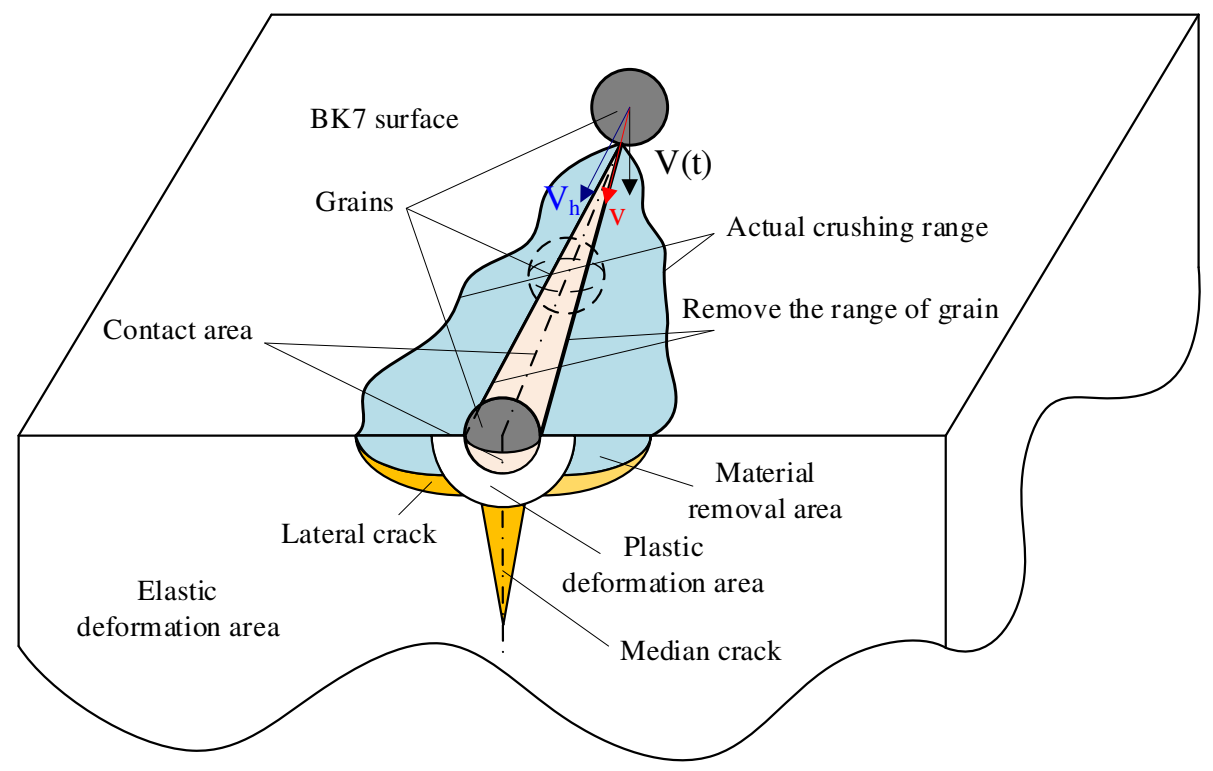

Fig 3 Indentation fracture model 
Suppose that the length of transverse crack and the depth of longitudinal crack produced by abrasive particles at the maximum pressure depth are respectively:

$C_{L}=\xi_{1}\left(P_{\max } / \mathrm{KI}_{\mathrm{d}}\right)^{3 / 4}$
$C_{H}=\xi_{2}\left(P_{\max } / \mathrm{H}_{v}\right)^{1 / 2}$

where, $\xi_{1}$ and $\xi_{2}$ are proportionality coefficient $\left(\xi_{1}=1.2, \xi_{2}=1.5\right), P_{\max }$ is maximum normal load applied.

Then the material removal volume of a single abrasive particle in a single vibration period $\mathrm{T}$ is $V_{s g}$ :

$V_{s g}=\frac{1}{3} \cdot \pi C_{L} C_{H} \cdot L=\frac{1}{3} \cdot \pi C_{L} C_{H} \cdot \mathrm{v}_{s} \cdot T$

Set a correction factor $\mathrm{K}(\mathrm{K}=1.2)$, the material removal volume of single abrasive particle on the micro convex peak and in the pore is respectively,

$$
\begin{aligned}
& V_{m l k}=\frac{\pi}{3} K \xi_{1} \xi_{2}\left(\frac{4 m \pi^{2} f^{2} k A_{0} \sin (2 \pi f t)+F_{0}}{3 \mathrm{KI}_{\mathrm{d}}}\right)^{\frac{3}{4}}\left(\frac{4 m \pi^{2} f^{2} k A_{0} \sin (2 \pi f t)+F_{0}}{\mathrm{H}_{v}}\right)^{\frac{1}{2}} \\
& V_{m l t}=\frac{\pi}{3} K \xi_{1} \xi_{2}\left(\frac{P_{\max }}{3 \mathrm{KI}_{\mathrm{d}}}\right)^{\frac{3}{4}}\left(\frac{P_{\max }}{\mathrm{H}_{v}}\right)^{\frac{1}{2}}
\end{aligned}
$$

\subsection{The material removal rate of numerous abrasive particles}

The total material removal volume in the UVAP is equal to the sum of the material removal volume of the abrasive particles in the pores and the abrasive particles removal volume in the micro convex peak of the polishing head. Among them, the removal volume of abrasive particles in pores and micro convex peaks in a single cycle are expressed as $V_{p}$ and $V_{v}$ respectively.

$$
\begin{aligned}
& V_{p}=\int_{0}^{\frac{T}{2}}\left|N_{s 1} \cdot \frac{V_{m l k}}{T} \cdot \frac{T}{2}\right| d t \\
& V_{v}=\int_{0}^{\frac{T}{2}}\left|\left(N_{t}-N_{s 1}\right) \cdot \frac{V_{m l t}}{T} \cdot \frac{T}{2}\right| d t
\end{aligned}
$$

Total material removal volume in a single vibration period $V$ is:

$V=V_{v}+V_{p}$

So, the per unit time MRR in the polishing process can be expressed as:

$M R R=\frac{V}{T}$

The material removal profile prediction is shown in Fig 4. 


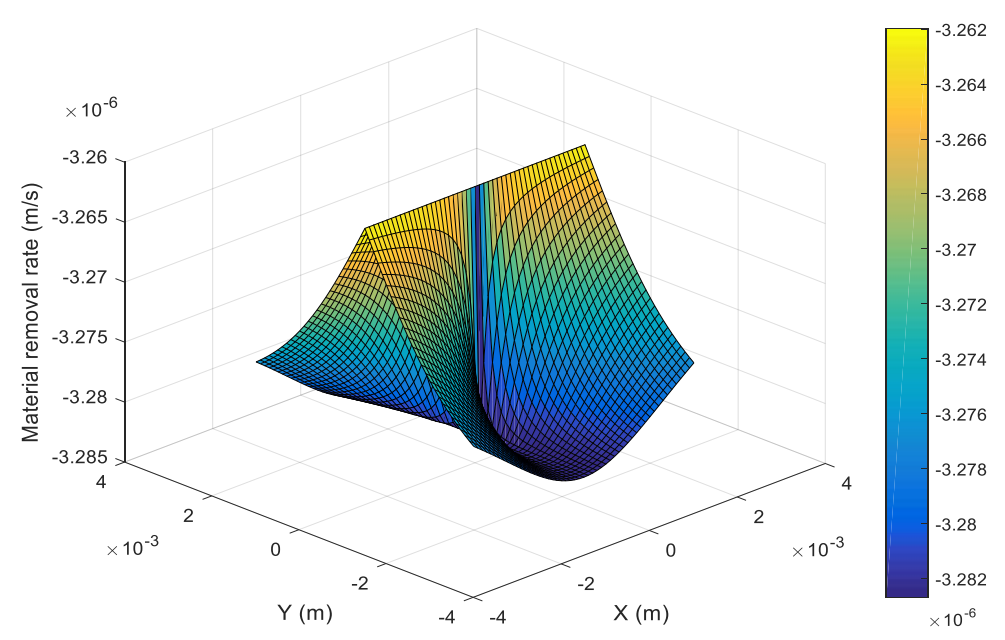

Fig 4 Predict polished 3D-surface-topography

\section{Analysis and discussions}

Theories analyses are carried out in this section for the MRR prediction model, the abrasive motion characteristics in the process of UVAP is analyzed, and the relationship between different process parameters (spindle speed, feed rate, abrasive particle diameter, ultrasonic amplitude and the flow-rate of polishing slurry) and MRR are analyzed in detail respectively to provide a theoretical basis for subsequent research.

\subsection{The simulation parameters conditions}

The detailed parameter is explained in this section. The associated material properties are listed in Table 1 and Table 2. The detailed simulation parameters are listed in Table 3.

Table 1

Material properties of BK7、Diamond.

\begin{tabular}{lllll}
\hline Material & Density $(\mathrm{g} / \mathrm{cm} 3)$ & $\begin{array}{l}\text { Young modulus } \\
(\mathrm{GPa})\end{array}$ & Poisson ratio & $\begin{array}{l}\text { Vickers hardness } \\
(\mathrm{GPa})\end{array}$ \\
\hline BK7 & 2.51 & 82 & 0.21 & 7.70 \\
Diamond & 3.52 & 1000 & 0.07 & 50 \\
\hline
\end{tabular}

Table 2

Properties of the polishing tool material

\begin{tabular}{|c|c|c|c|c|}
\hline Material & $\operatorname{Density}(\mathrm{g} / \mathrm{cm} 3)$ & $\begin{array}{l}\text { Young modulus } \\
\text { (MPa) }\end{array}$ & Poisson ratio & $\begin{array}{l}\text { Shore A } \\
\text { Hardness }\end{array}$ \\
\hline Polyurethane & 0.49 & 2.29 & 0.47 & 73 \\
\hline
\end{tabular}


Table 3

Polishing parameters for the UVAP calculations of the model

\begin{tabular}{ll}
\hline Parameter & Value \\
\hline Polishing-tool dimension $R_{0} / \mathrm{mm}$ & 2.5 \\
Abrasive-particle size $d / \mu \mathrm{m}$ & 0.5 \\
Flow-rate of polishing slurry $Q / \mathrm{ml} \cdot \mathrm{min}^{-1}$ & 12 \\
polishing force $F / \mathrm{N}$ & 3 \\
Spindle speed of ultrasonic electric-spindle $\omega_{p} / \mathrm{rpm}$ & 8000 \\
Feed speed of ultrasonic electric-spindle $V_{j} / \mathrm{mm} / \mathrm{min}$ & 400 \\
Frequency of ultrasonic generator $f / \mathrm{kHz}$ & 25 \\
Amplitude of ultrasonic generator $A / \mu \mathrm{m}$ & 5 \\
\hline
\end{tabular}

\subsection{Motion analyses of the abrasive particles}

From the above analysis, it can be seen the part of the abrasive particles in the polishing liquid embedded the polishing pad micro-raised part with the polishing pad movement. Another part of the abrasive particles exists in the polishing pad pores, forming the free abrasive particles. The two kinds of abrasive particles movement form are slightly different.

\subsubsection{Motion analyses of the embedded abrasive particles}

According to Fig. 2, the displacement equation of the contact embedded abrasive particle $\mathrm{M}(\mathrm{x}, \mathrm{y})$ could be expressed as:

$$
X(\mathrm{t})=\left(\begin{array}{l}
l \cos \left(\omega_{\mathrm{q}} \mathrm{t}\right)+\mathrm{v}_{\mathrm{j}} t \\
l \sin \left(\omega_{\mathrm{q}} \mathrm{t}\right) \\
A \sin (2 \pi f t)
\end{array}\right)
$$

where, $l$ is the distance from point $\mathrm{M}$ to point $\mathrm{O}, \omega_{p}$ is spindle speed, $A$ and $f$ are ultrasonic amplitude and frequency respectively. The trajectory of abrasive particles embedded the polishing pad can be obtained from the above formula, as shown in the Fig 5. As shown in Fig 6, the instantaneous velocity of point $M(x, y)$ is composed of the sub motions in $\mathrm{X}, \mathrm{Y}$ and $\mathrm{Z}$ directions:

$\mathrm{V}(\mathrm{t})=\left(\begin{array}{l}-l \sin \left(\omega_{\mathrm{q}} \mathrm{t}\right)+\mathrm{v}_{\mathrm{j}} \\ l \omega_{\mathrm{q}} \cos \left(\omega_{\mathrm{q}} \mathrm{t}\right) \\ 2 \pi f A \cos (2 \pi f t)\end{array}\right)$

From the above formula, the instantaneous velocity $\mathrm{V}$ at point $\mathrm{M}$ is:

$$
V=\sqrt{v(\mathrm{t})^{2}+V_{s}^{2}}=\sqrt{(2 \pi f A \cos (2 \pi f t))^{2}+\left(\mathrm{V}_{\mathrm{r}}^{2}+\mathrm{V}_{\mathrm{j}}^{2}-2 \mathrm{~V}_{\mathrm{r}} \mathrm{V}_{\mathrm{j}} \cos (\pi-\theta)\right)^{2}}
$$


As shown in Fig 6, in the XOY plane, the magnitude and direction of $V_{r}$ change with time due to the rotation of the spindle, and the axial movement changes periodically with the spindle, so the instantaneous speed and position also change periodically with time. When the angle between $V_{r}$ and $V_{j}$ is $0^{\circ}$, the horizontal direction and speed $V_{s}$ are the largest, and when the angle is $180^{\circ}$, the sum speed is the smallest. During the polishing process, the feed speed $V_{j}$ remains constant, $V_{r}$ size and direction changes all the time, and $V_{r}=\omega_{\mathrm{q}} \times r$, the speed of the points at different distances from the $\mathrm{O}$ point also changes, as shown in Fig 7, the M1, M2, M3 three points of horizontal and speed $V_{s}$ is drawn, it can be seen that the same angle under the different positions of the speed curve trend is the same, the further away from the $\mathrm{O}$ point the greater the speed.

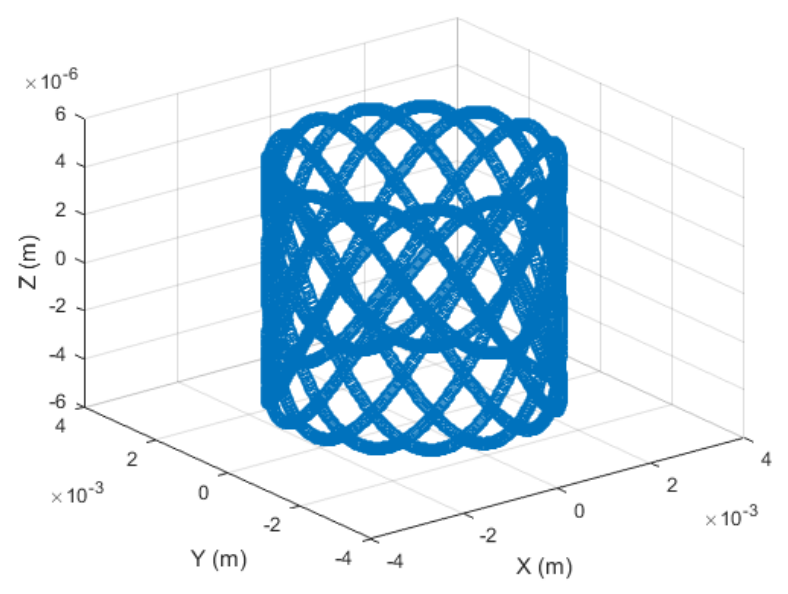

Fig 5 Trajectory of the embedded abrasive particles movement

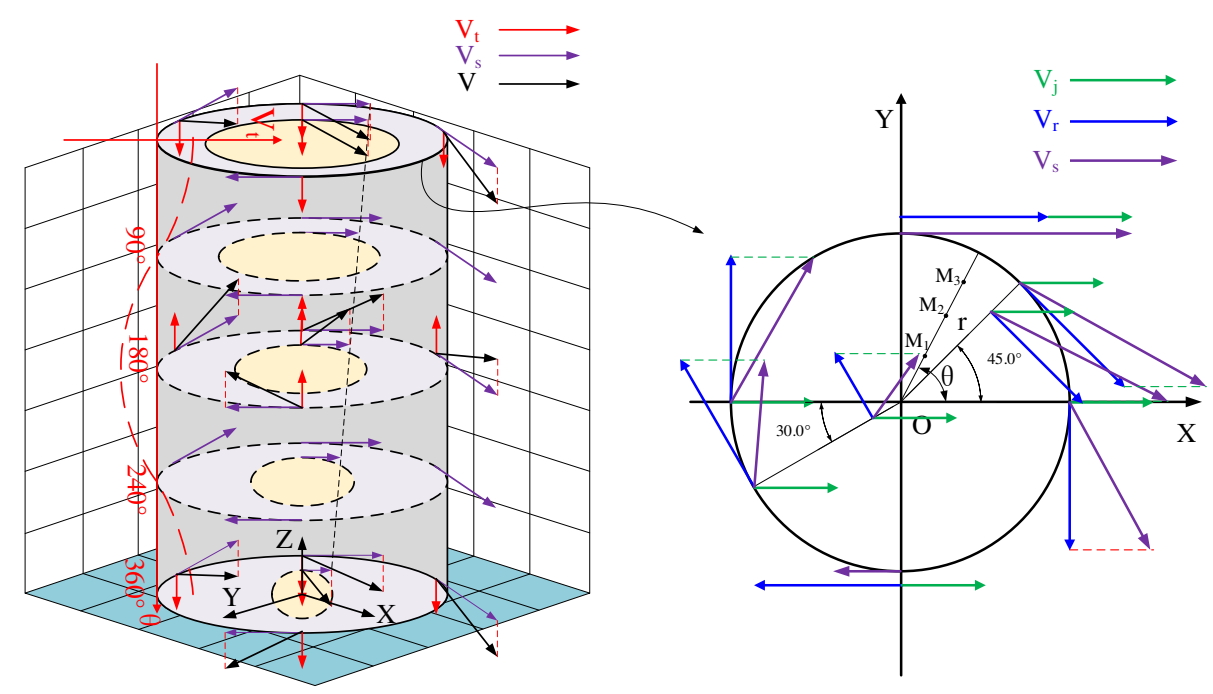

Fig 6 Schematic diagram of instantaneous speed 


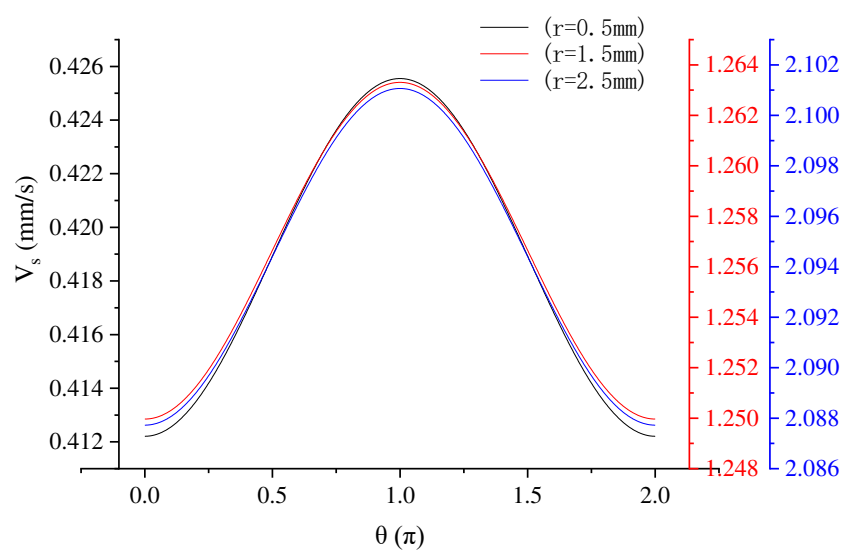

Fig 7 M1, M2, M3 speed curve

It can be seen from Eq. 20 that the factor that has the greatest influence on the law of abrasive particles motion is the spindle speed. The trajectories of abrasive particles at different spindle speeds are shown in Fig 5. As can be seen from Fig 6, the distribution of abrasive particles motion trajectory under different rotational speeds is very different. When the spindle speed of is higher, the horizontal relative velocity is higher, the instantaneous velocity is higher, the change frequency of abrasive trajectory is faster, and the number of scratches on the workpiece per unit time is increased, which helps to improve the polishing accuracy and efficiency.

\subsubsection{Motion analyses of the free abrasive particles}

The free abrasive particles are only affected by the axial ultrasonic vibration, so they do periodic simple harmonic vibration in the axial direction. The free abrasive particles motion trajectories under different amplitudes as shown in Fig 8 and the free abrasive particle velocity curves at different frequencies are shown in the Fig 9. From Fig. 8 and Fig. 9 that the greater the ultrasonic amplitude is, the greater the motion distance of abrasive particles is; the higher the ultrasonic frequency is, the more times of scratching with the workpiece in unit time is, and the higher the MRR is.

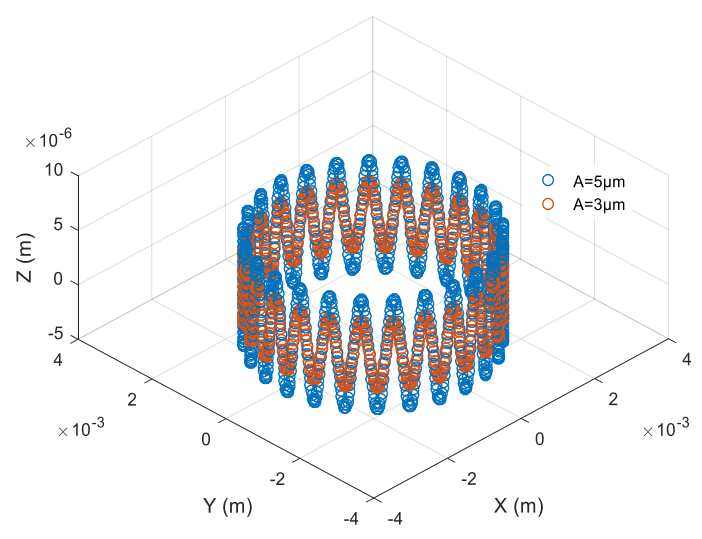

Fig. 8 Free abrasive particle motion trajectory with different amplitude 


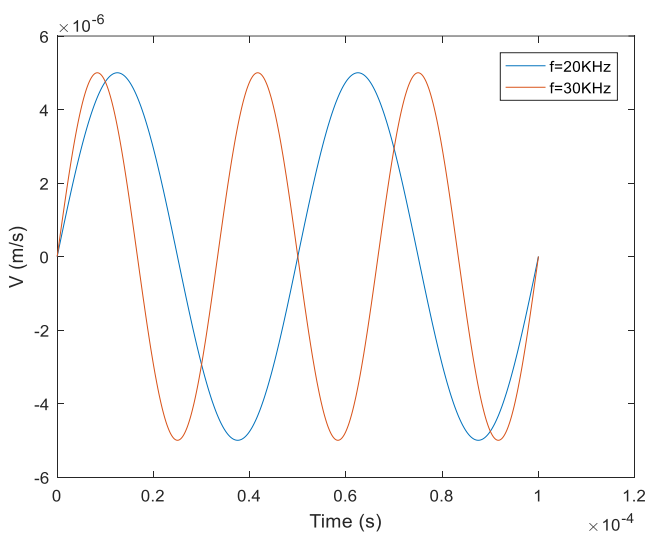

Fig. 9 Free abrasive particle velocity curves at different frequencies

\subsection{The relationship between nominal distance and material removal rate}

It can be seen from the above analysis that the actual contact area between the polishing pad and the workpiece is directly related to the nominal diameter. Only the micro convex peak of the polishing pad higher than the nominal diameter can contact the workpiece, and this parameter directly affects the polishing accuracy and efficiency.

\subsubsection{The relationship between nominal distance and actual contact area}

Under the same conditions, the larger the nominal distance is, the smaller the actual contact area is, and the values of nominal distance and actual contact area can be fitted into a curve by equation, as shown in Fig 10. It can be seen from figure 10 that there is a negative correlation between the nominal distance and the actual contact area. The curve shows that the attenuation rate of the actual contact area and the nominal distance is getting lower and lower, and when the nominal distance is $6.25 \times 10^{-5} \mathrm{~m}$, the polishing pad is disconnected from the workpiece.

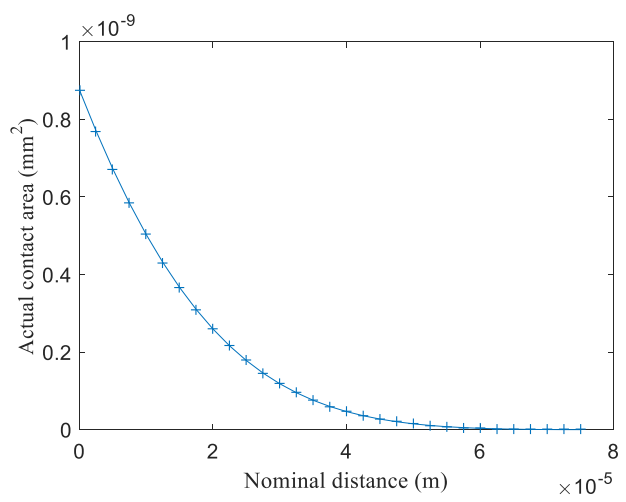

Fig 10 Relationship curve between nominal distance and actual contact area 


\subsubsection{The relationship between nominal distance and material removal}

rate

It can be seen from the pressure formula $P=F / S$, when $\mathrm{F}$ is constant, the smaller the actual contact area, the greater the pressure between the contact surfaces, and as shown in Fig 11, the greater the nominal distance d, the smaller the actual contact area, the greater the pressure, and the greater the MRR. Fig 11 plots the relationship between the nominal distance $d$ and the MRR, and it can be seen from the figure that the value of $d$ is negatively correlated with the MRR, and when $d$ is greater than $22 \mu \mathrm{m}$, the MRR decreases rapidly and approaches zero.

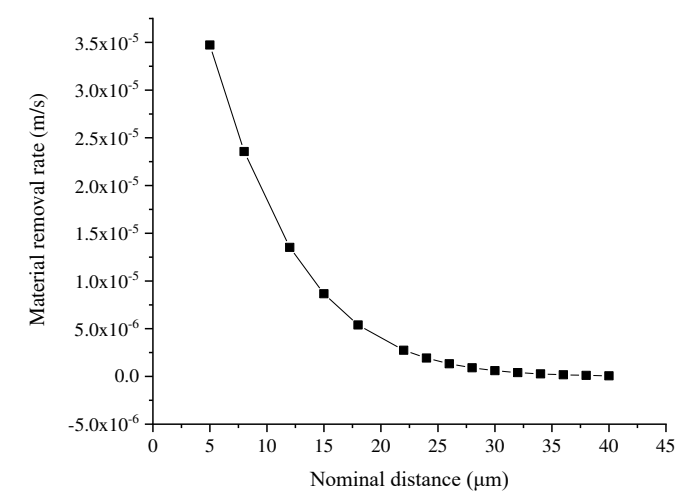

Fig 11 Effect of nominal distance on material removal rate

\subsection{The relationship between different process parameters and MRR}

\subsubsection{The relationship between spindle speed and material removal rate}

The MRR at different spindle speeds are shown in Fig 12. In the simulation analysis, the spindle speed varies from $2000 \mathrm{rpm}$ to $8000 \mathrm{rpm}$, while the other process parameters are fixed as $d=0.5 \mu \mathrm{m}, F=3 \mathrm{~N}, V_{j}=400 \mathrm{~mm} / \mathrm{min}, f=25 \mathrm{kHz}, A=5 \mu \mathrm{m}$, $Q=12 \mathrm{ml} \cdot \mathrm{min}^{-1}$. It can be seen the faster spindle speed the greater the MRR, and the two are proportional to each other. It can be seen from Eq 9, 10 and 12, that the spindle speed directly affects the relative speed $V_{s}$. The faster spindle speed is, the faster the relative speed is, the more times the workpiece surface is scratched in unit time, the larger the removal volume of single abrasive particle is, and the greater the MRR is. However, in the actual polishing, the spindle speed is limited by the stiffness of the machine tool, and can not be increased indefinitely. Only when the processing conditions are met, the spindle speed can be increased as much as possible under the processing conditions to improve the MRR. 


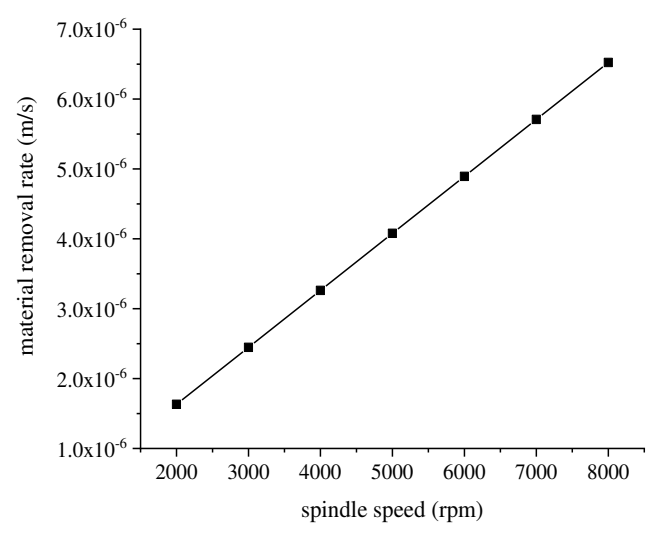

Fig 12 Effect of spindle speed on material removal rate

\subsubsection{The relationship between feed speed and material removal rate}

MRR at different feed speeds is shown in Fig 13 , settings include $d=0.5 \mu \mathrm{m}$, $F=3 \mathrm{~N}, \omega_{p}=8000 \mathrm{rpm}, f=25 \mathrm{kHz}, A=5 \mu \mathrm{m}, Q=12 \mathrm{ml} \cdot \mathrm{min}^{-1}$.It can be seen that the faster the feed speed the greater the MRR. It can be seen from Eq 10, and 12 that the speed of the spindle directly affects the relative speed $V_{j}$. The higher the feed speed, the higher the relative speed, but the difference between the feed speed and the spindle speed is very large, and the feed speed has limited influence on the relative speed. In the actual polishing, the feed rate should be selected appropriately to prevent too high feed rate leading to low polishing accuracy or too low feed rate leading to lower machining efficiency.

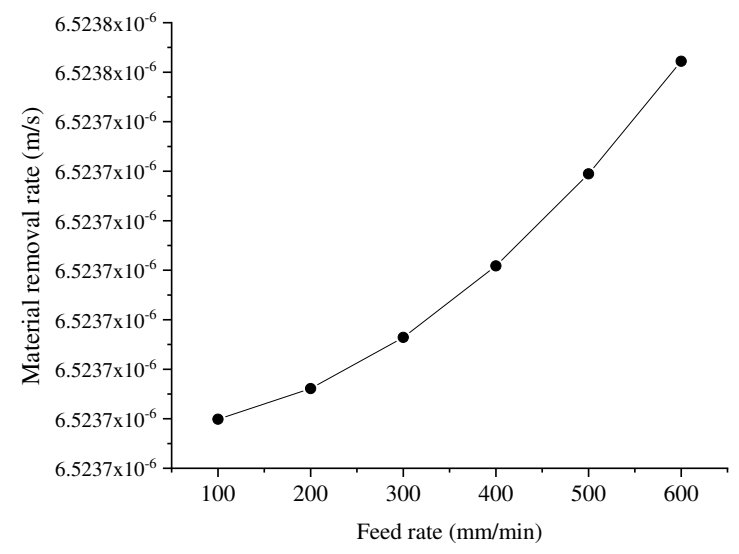

Fig 13 Effect of feed speed on material removal rate 


\subsubsection{The relationship between abrasive particle size and material}

removal rate

The relationship between different abrasive particle diameters and MRR is shown in Fig 14, which shows that the larger the abrasive particle diameter, the lower the MRR. when the abrasive particle diameter increases from $0.5 \mu \mathrm{m}$ to $1 \mu \mathrm{m}$, the MRR decreases rapidly. The simulation settings are $F=3 \mathrm{~N}, \omega_{p}=8000 \mathrm{rpm}$, $V_{j}=400 \mathrm{~mm} / \mathrm{min}, f=25 \mathrm{kHz}, A=5 \mu \mathrm{m}, Q=12 \mathrm{ml} \cdot \mathrm{min}^{-1}$. When the abrasive particle size increases, the removal volume of a single abrasive particle increases, but the linear density of the abrasive decreases (when the mass concentration or volume concentration of the polishing slurry is a fixed value), and the number of abrasive particles embedded in the polishing tool per unit area decreases. That is to say, the number of effective abrasive particles decreases greatly, resulting in the decrease of MRR.

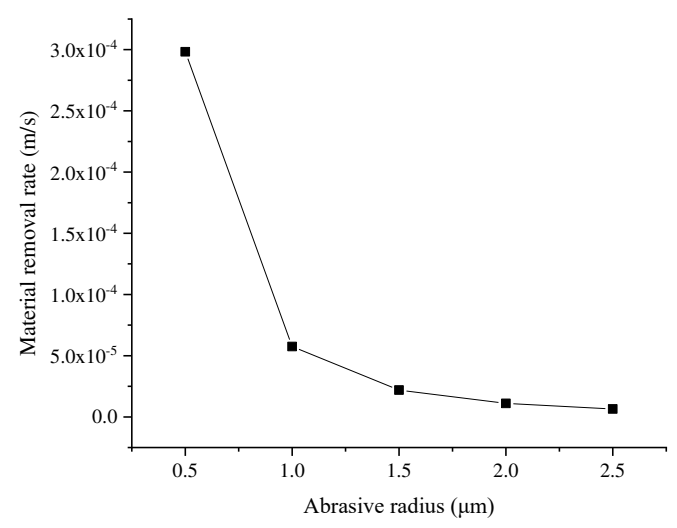

Fig 14 Effect of abrasive particle radius on material removal rate

\subsubsection{The relationship between ultrasonic amplitude and material removal}

rate

The relationship between different ultrasonic amplitude and MRR is shown in Fig 15, which shows that the ultrasonic amplitude and MRR are positively correlated, and the MRR increases with the increase of ultrasonic amplitude. And polishing settings are $d=0.5 \mu \mathrm{m}, F=3 \mathrm{~N}, \omega_{p}=8000 \mathrm{rpm}, V_{j}=400 \mathrm{~mm} / \mathrm{min}, f=25 \mathrm{kHz}, Q=12 \mathrm{ml} \cdot \mathrm{min}^{-1}$. The ultrasonic amplitude directly affects the motion characteristics of the abrasive particles during the polishing. The larger the amplitude, the larger the motion range, and the MRR increases in the same time. 


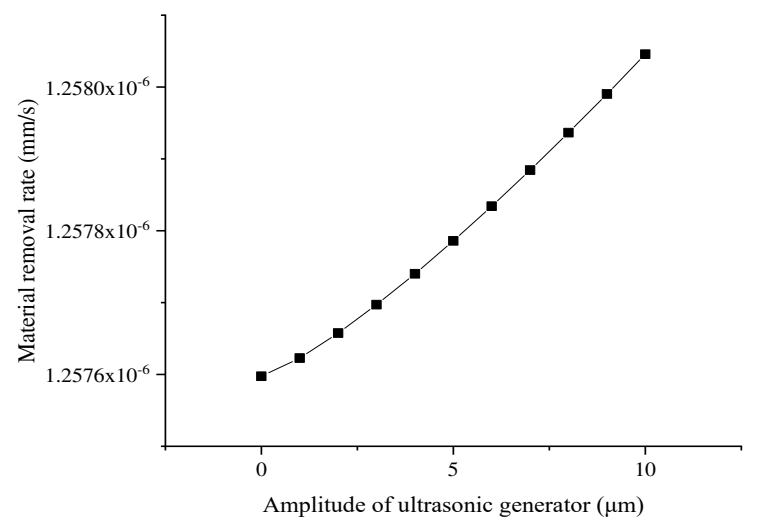

Fig 15 Effect of amplitude of ultrasonic generator on material removal rate

\subsubsection{The relationship between flow-rate of polishing slurry and material} removal rate

The relationship between different polishing slurry flow rates and MRR is shown in Fig 16, simulation settings include $d=0.5 \mu \mathrm{m}, F=3 \mathrm{~N}, \omega_{p}=8000 \mathrm{rpm}, V_{j}=400 \mathrm{~mm} / \mathrm{min}$, $f=25 \mathrm{kHz}, A=5 \mu \mathrm{m}$. It can be seen the flow rate of polishing slurry and MRR are approximately proportional, the more polishing slurry flow rate the greater the MRR. The effective abrasive particles increase with the increase of the slurry flow rate, which can improve the MRR. In the actual polishing, too little polishing slurry flow will result in insufficient abrasive particles, affecting polishing accuracy. However, excessive use of polishing slurry wastes resources, polishing fluid affects the environment, and does not conform to the green processing trend.

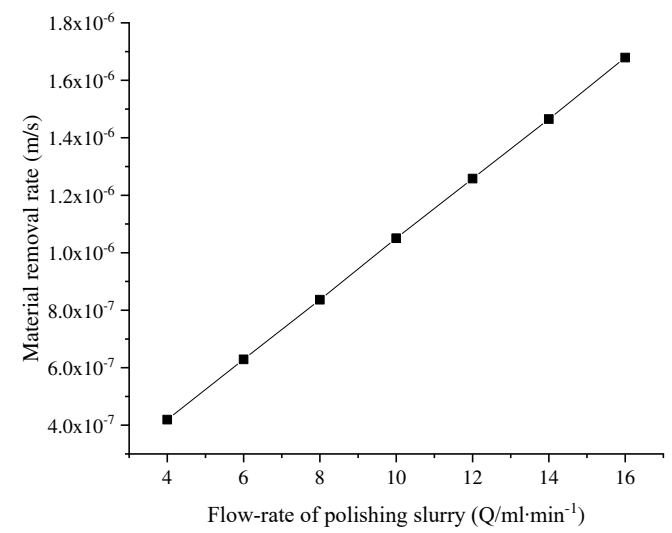

Fig 16 Effect of flow-rate of polishing slurry on material removal rate 


\section{Conclusions}

UVAP can effectively improve the polishing efficiency. In this paper, the process parameters are qualitatively analyzed, and the MRR model is established. In order to better apply the UVAP technology to actual production, this paper draws the following conclusions:

1. The MRR model of UVAP of optical glass (BK7) based on ultrasonic atomization was established by analyzing the abrasive particle motion during the polishing, which can be used to predict the material removal profile and analyze the effect of different process parameters on the MRR.

2. In this paper, the influence of technological parameters (spindle speed, feed speed, abrasive diameter, ultrasonic amplitude, polishing slurry flow rate) on MRR in the polishing process was analyzed qualitatively. Through a detailed analysis of a single variable, it is concluded that the MRR is approximately proportional to the spindle speed and the polishing slurry flow rate. The feed rate and ultrasonic amplitude are positively related to the MRR while negatively related to the diameter of the abrasive particles. Among them, the spindle speed has the greatest influence on MRR, followed by the abrasive diameter and polishing slurry flow rate, while the ultrasonic amplitude and feed speed have less influence on MRR.

3. The characteristics of abrasive particle motion are changed by the introduction of ultrasonic vibration. The trajectory of the embedded abrasive particles is a space sine curve, and the free abrasive particles do a simple harmonic motion in the vertical direction. Each abrasive particle makes intermittent contact with the BK7 specimen only the first half vibration period, which can reduce micro-polishing force and improve machining accuracy. Ultrasonic vibration can greatly improve the impact between the abrasive particles and the workpiece, which can improve the polishing efficiency. Ultrasonic vibration and polishing efficiency are directly affected by ultrasonic frequency and amplitude.

Authors' contribution Yingdong Liang: conceptualization, methodology, investigation, data curation, visualization, writing - original draft

Chao Zhang: investigation, writing - review and editing

Xin Chen: investigation, writing - review and editing

Tianqi Zhang: investigation, writing — review and editing

Tianbiao Yu: resources, supervision, project administration

Ji Zhao: resources, supervision, project administration

Funding This work was supported by the Major State Basic Research Development Program of China [Grant No. 2017YFA0701200]; the Key Project of National Natural Science Foundation of China [Grant No.U1508206];

Data availability Not applicable. 


\section{Declarations}

Ethical approval Not applicable.

Consent to participate Not applicable.

Consent to publish Not applicable.

Competing interests The authors declare no competing interests.

\section{References}

1. Yu T, Zhang T, Yang T, Zhao J (2019) CFD simulation and experimental studies of suspension flow field in ultrasonic polishing. J Mater Process Technol 266:. https://doi.org/10.1016/j.jmatprotec.2018.11.034

2. Thoe TB, Aspinwall DK, Wise MLH (1998) Review on ultrasonic machining. Int J Mach Tools Manuf 38:. https://doi.org/10.1016/S0890-6955(97)00036-9

3. Pan R, Zhong B, Chen D, et al (2018) Modification of tool influence function of bonnet polishing based on interfacial friction coefficient. Int J Mach Tools Manuf 124:. https://doi.org/10.1016/j.ijmachtools.2017.09.003

4. Cao ZC, Cheung CF, Ren M (2016) Modelling and characterization of surface generation in Fluid Jet Polishing. Precis Eng 43:. https://doi.org/10.1016/j.precisioneng.2015.09.005

5. Lamikiz A, Sánchez JA, López de Lacalle LN, Arana JL (2007) Laser polishing of parts built up by selective laser sintering. Int J Mach Tools Manuf 47:. https://doi.org/10.1016/j.ijmachtools.2007.01.013

6. Bedi TS, Singh AK (2016) Magnetorheological methods for nanofinishing - a review. Part Sci Technol 34:. https://doi.org/10.1080/02726351.2015.1081657

7. Yang Z, Zhu L, Zhang G, et al (2020) Review of ultrasonic vibration-assisted machining in advanced materials. Int J Mach Tools Manuf 156:103594. https://doi.org/10.1016/j.ijmachtools.2020.103594

8. Preston F. (1927) The theory and design of plate glass polishing machine. Trans Opt Soc 27:214

9. Sun J, Zhang LC, Mai YW, et al (2000) Computational modelling of a precision optical lens polishing process on small radius spherical surfaces. J Mater Process Technol 105:204-213. https://doi.org/10.1016/S0924-0136(00)00623-3

10. Wang CC, Lin SC, Hochen H (2002) A material removal model for polishing glass-ceramic and aluminum magnesium storage disks. Int J Mach Tools Manuf 42:979-984. https://doi.org/10.1016/S0890-6955(02)00004-4

11. Zhang L, Tam HY, Yuan CM, et al (2002) On the removal of material along a polishing path by fixed abrasives. Proc Inst Mech Eng Part B J Eng Manuf 216:1217-1225. https://doi.org/10.1243/095440502760291772 
12. Zhang L, Tam HY, Yuan CM, et al (2002) An investigation of material removal in polishing with fixed abrasives. Proc Inst Mech Eng Part B J Eng Manuf 216:103-112. https://doi.org/10.1243/0954405021519591

13. Wang G, Wang Y, Xu Z (2009) Modeling and analysis of the material removal depth for stone polishing. J Mater Process Technol 209:2453-2463. https://doi.org/10.1016/j.jmatprotec.2008.05.041

14. Zhong ZW, Tian YB, Ng JH, Ang YJ (2014) Chemical mechanical polishing (CMP) processes for manufacturing optical silicon substrates with shortened polishing time. Mater Manuf Process 29:15-19. https://doi.org/10.1080/10426914.2013.852206

15. Fan C, Zhao J, Zhang L, et al (2014) Modeling and analysis of the material removal profile for free abrasive polishing with sub-aperture pad. J Mater Process Technol 214:285-294. https://doi.org/10.1016/j.jmatprotec.2013.09.010

16. G August, S Roland (1963) Ultrasonic machining

17. Agarwal S (2015) On the mechanism and mechanics of material removal in ultrasonic machining. Int J Mach Tools Manuf 96:1-14. https://doi.org/10.1016/j.ijmachtools.2015.05.006

18. Zhang T, Wang Z, Yu T, et al (2021) Modeling and prediction of generated local surface profile for ultrasonic vibration-assisted polishing of optical glass BK7. J Mater Process Technol 289:116933. https://doi.org/10.1016/j.jmatprotec.2020.116933

19. Han G, Zhao J, Wang X (2017) Research on unbounded abrasive polishing process with assisted ultrasonic vibration of workpiece. Int J Adv Manuf Technol 88:209-218. https://doi.org/10.1007/s00170-016-8767-1

20. Wang Y, Lin B, Wang S, Cao X (2014) Study on the system matching of ultrasonic vibration assisted grinding for hard and brittle materials processing. Int J Mach Tools Manuf 77:66-73. https://doi.org/10.1016/j.ijmachtools.2013.11.003

21. Kobara H, Tamiya M, Wakisaka A, et al (2010) Relationship between the size of mist droplets and ethanol condensation efficiency at ultrasonic atomization on ethanol-water mixtures. AIChE J 56:810-814. https://doi.org/10.1002/aic.12008

22. Zhang Y, Yuan S, Wang L (2021) Investigation of capillary wave, cavitation and droplet diameter distribution during ultrasonic atomization. Exp Therm Fluid Sci 120:. https://doi.org/10.1016/j.expthermflusci.2020.110219

23. Kudo T, Sekiguchi K, Sankoda K, et al (2017) Effect of ultrasonic frequency on size distributions of nanosized mist generated by ultrasonic atomization. Ultrason Sonochem 37:. https://doi.org/10.1016/j.ultsonch.2016.12.019

24. Greenwood JA (1997) Analysis of elliptical Hertzian contacts. Tribol Int 30:. https://doi.org/10.1016/S0301-679X(96)00051-5

25. Yu TK, Yu CC, Orlowski M (1993) Statistical polishing pad model for Chemical-Mechnical polishing. In: Technical Digest - International Electron Devices Meeting

26. Greenwood, J.A., Williamson JB. (1966) Contact of nominally flat surfaces. Proc R Soc London Ser A Math Phys Sci 295:. https://doi.org/10.1098/rspa.1966.0242 
27. Burton G, Goo CS, Zhang Y, Jun MBG (2014) Use of vegetable oil in water emulsion achieved through ultrasonic atomization as cutting fluids in micro-milling. J Manuf Process 16:.

https://doi.org/10.1016/j.jmapro.2014.04.005

28. GRUNINGER MF, LAWN BR, FARABAUGH EN, WACHTMAN JB (1987)

Measurement of Residual Stresses in Coatings on Brittle Substrati by Indentation Fracture. J Am Ceram Soc 70:

https://doi.org/10.1111/j.1151-2916.1987.tb05006.x 
Figures

\section{Loose porous structure}

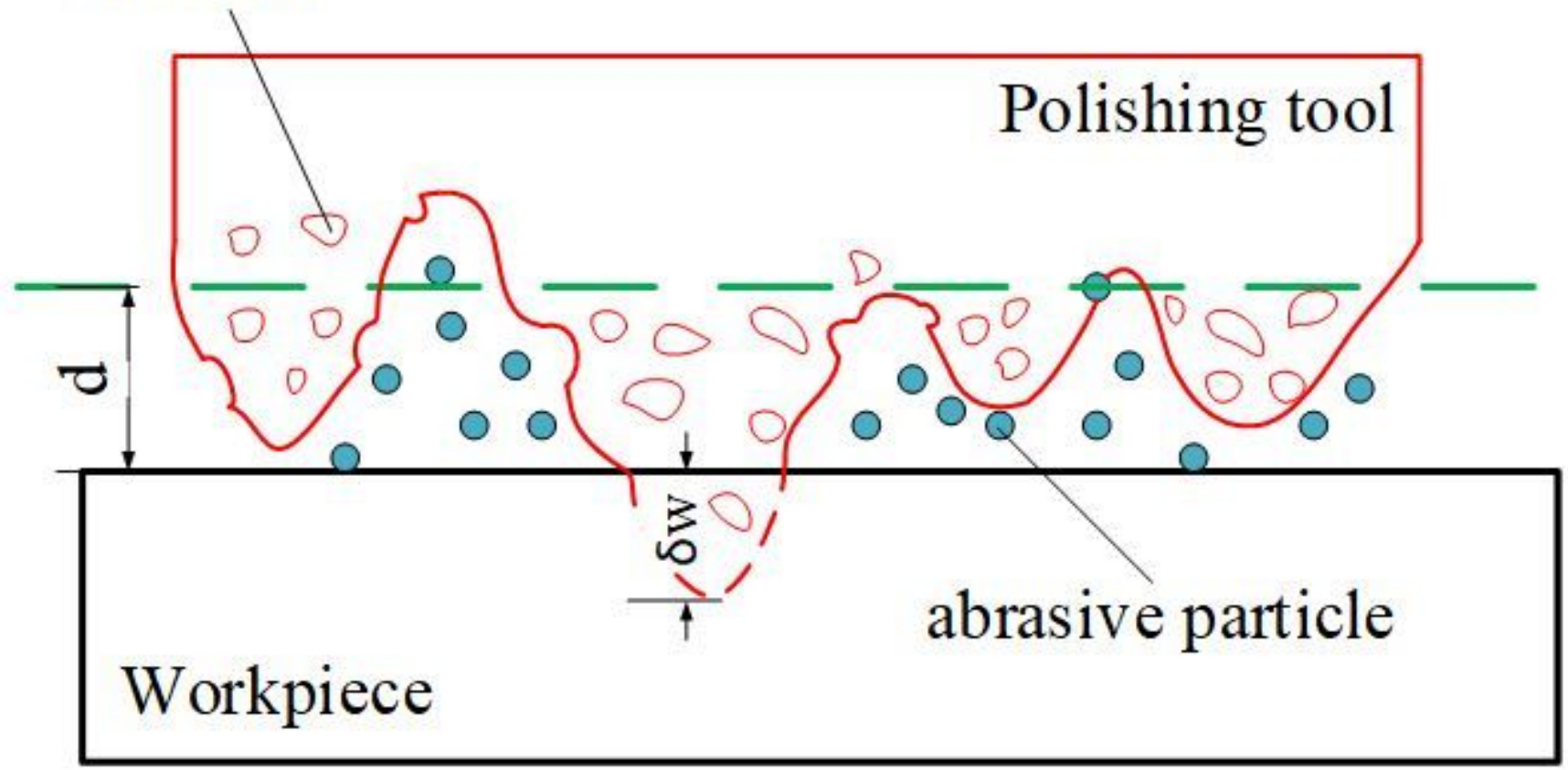

Figure 1

Interactions between polishing tool, abrasive particle and workpiece.

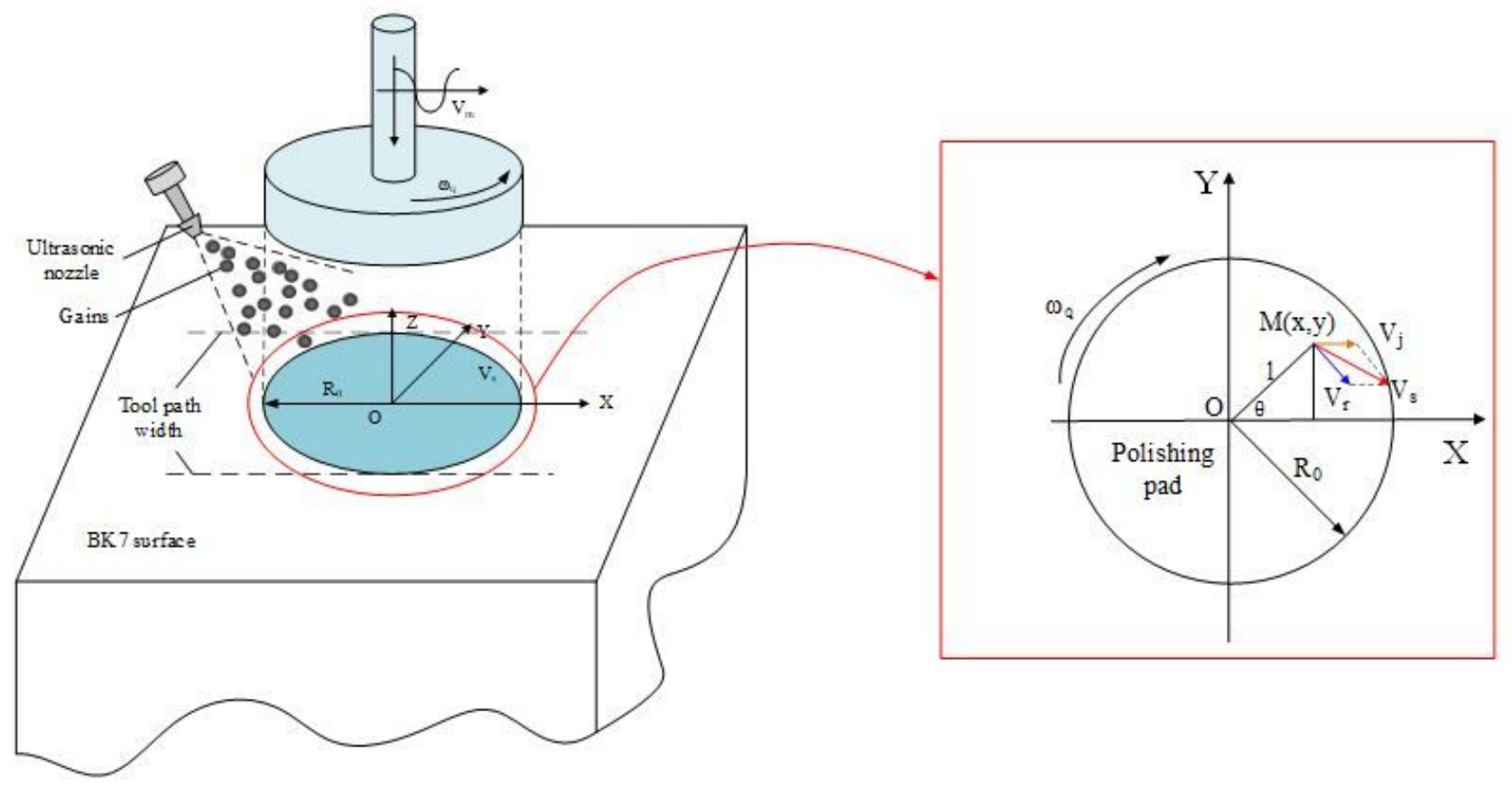

Figure 2 
Schematic diagram of relative velocity

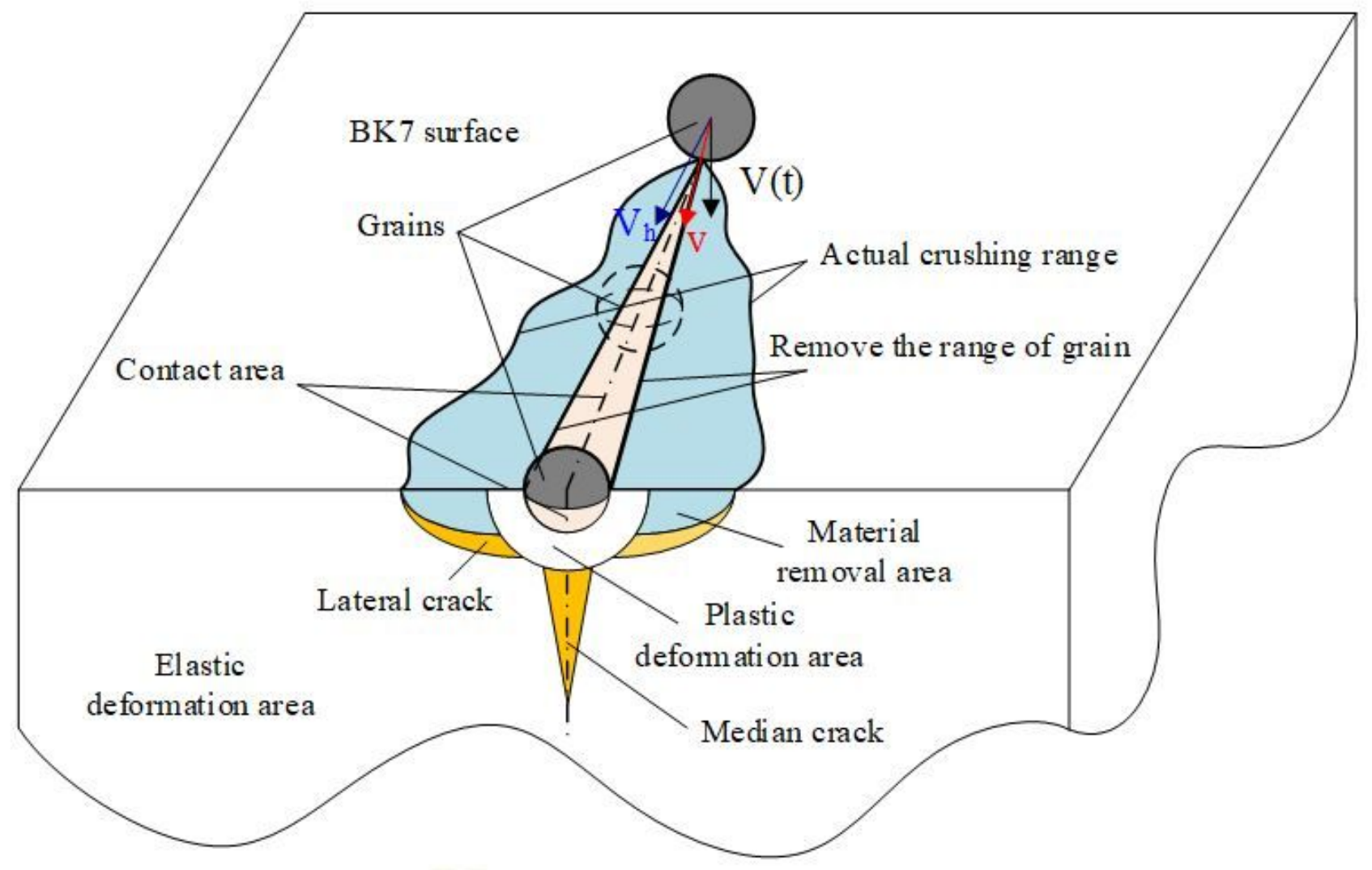

Figure 3

Indentation fracture model 


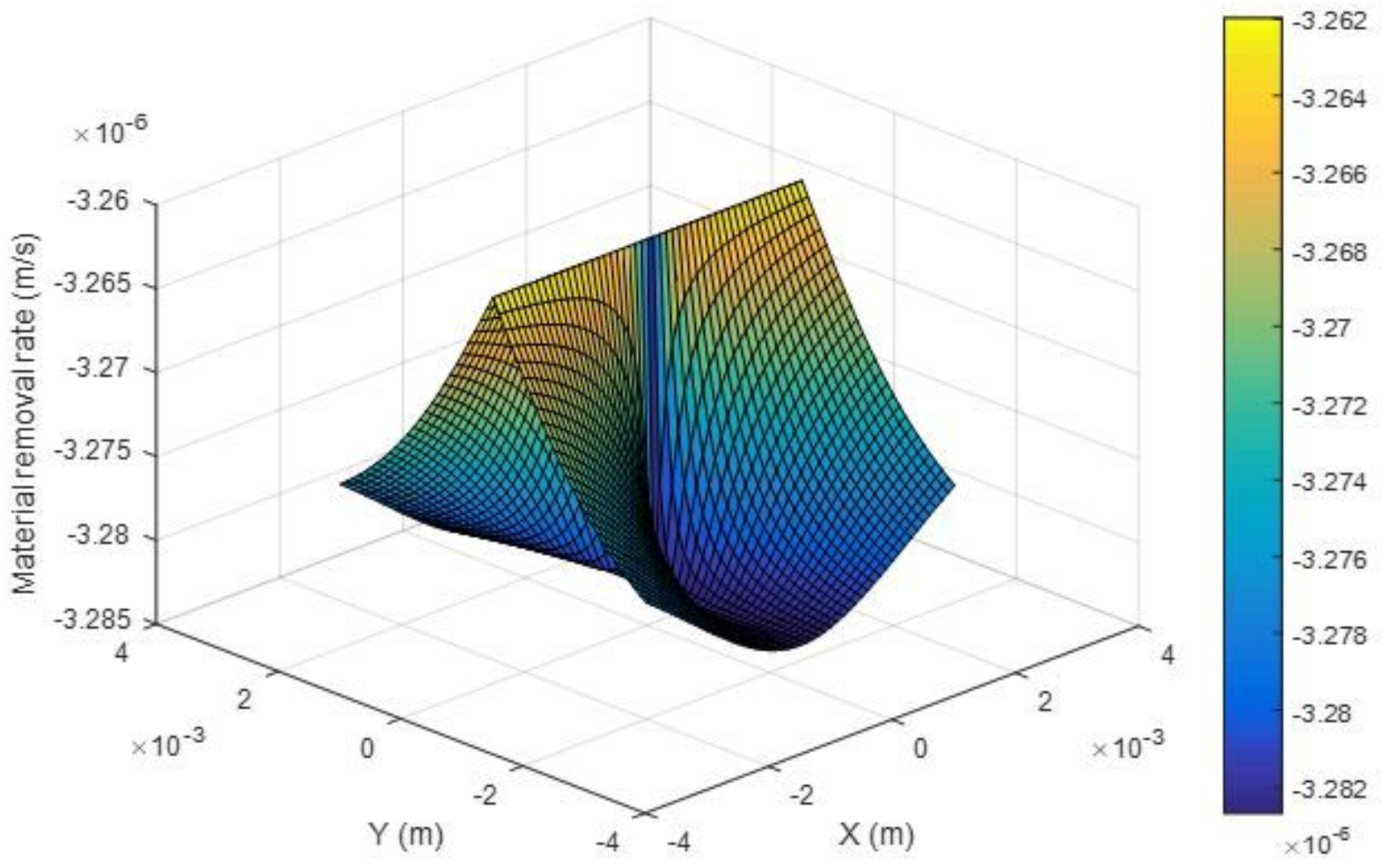

Figure 4

Predict polished 3D-surface-topography 


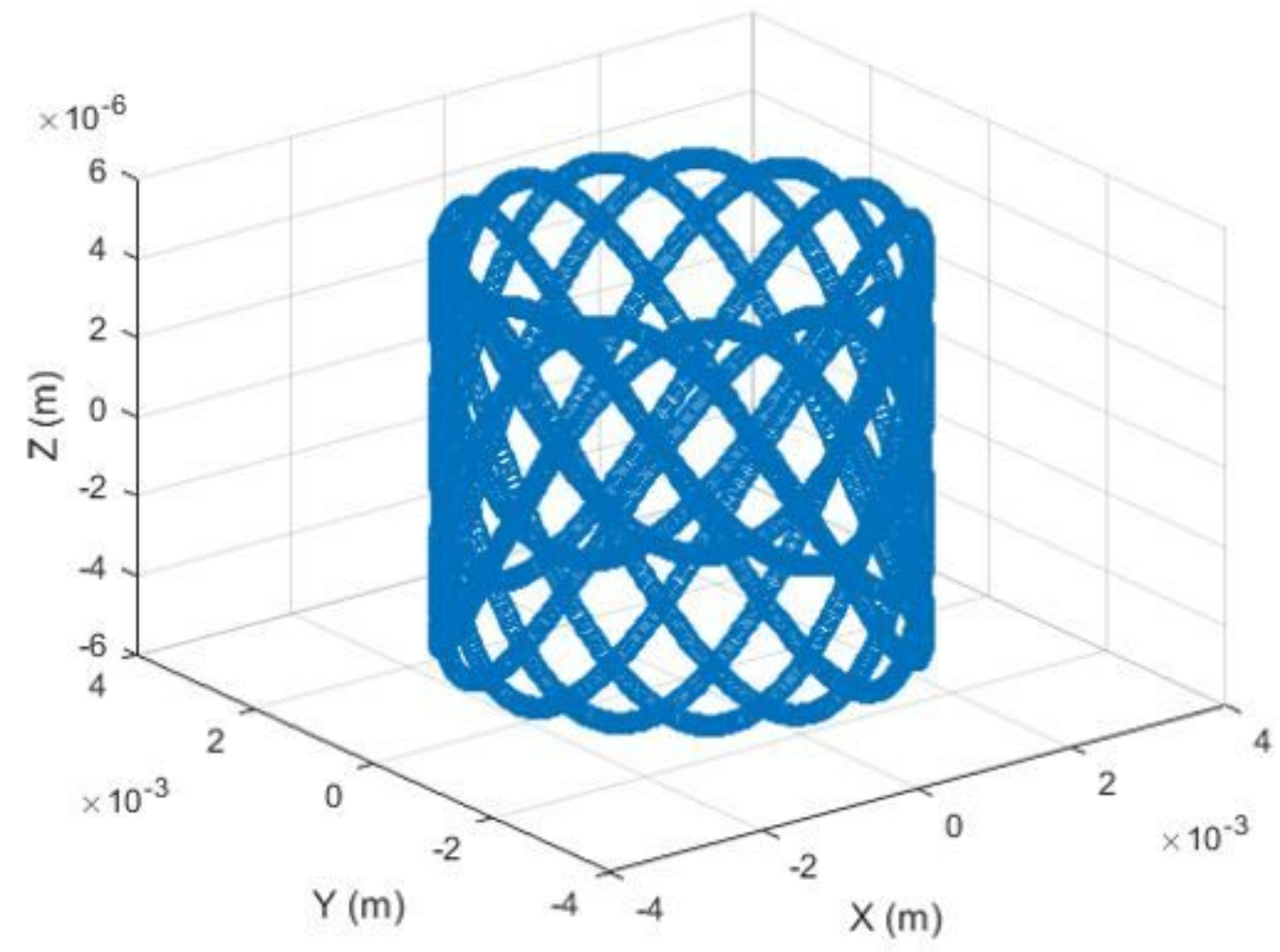

Figure 5

Trajectory of the embedded abrasive particles movement

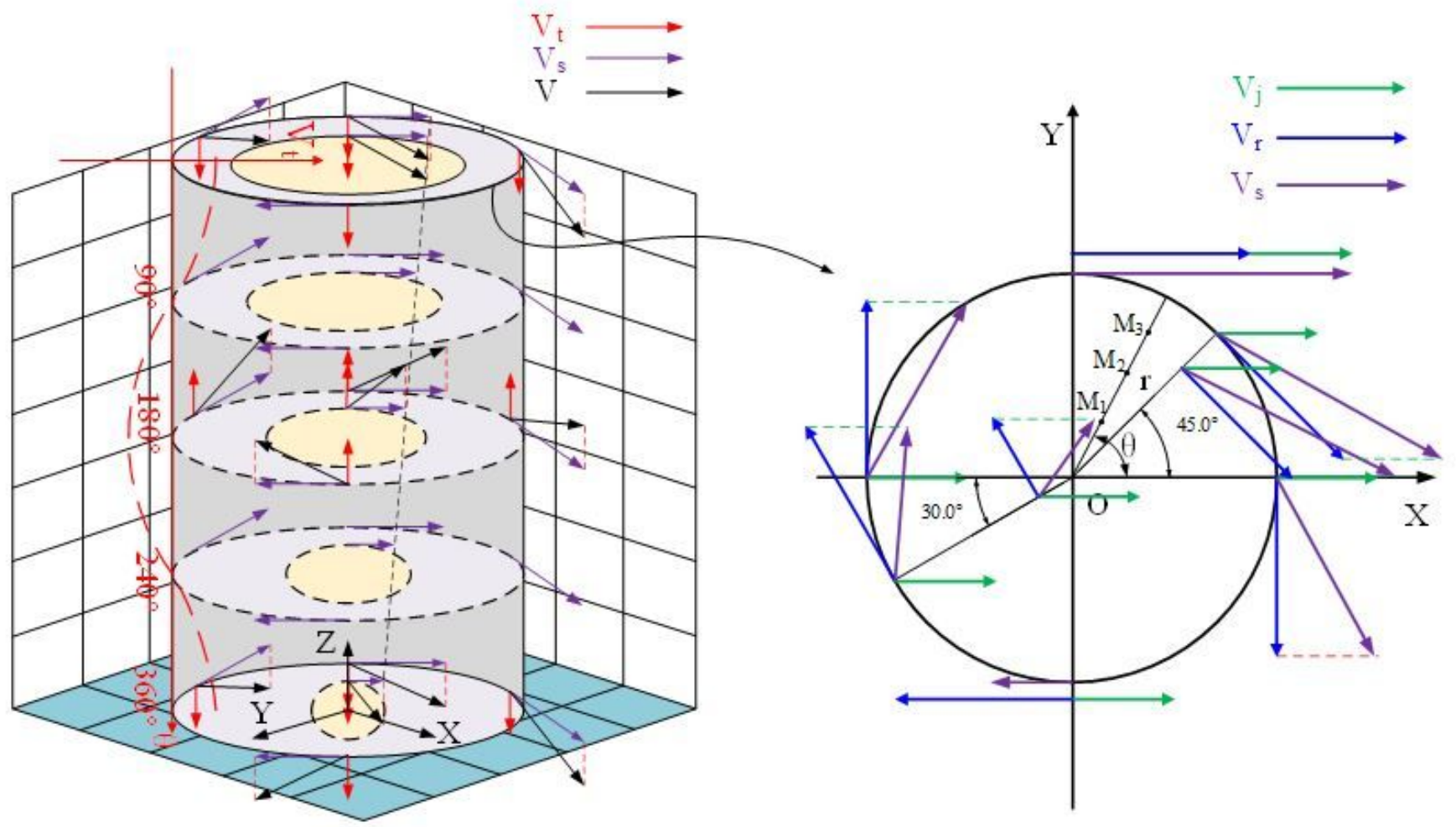

Figure 6 


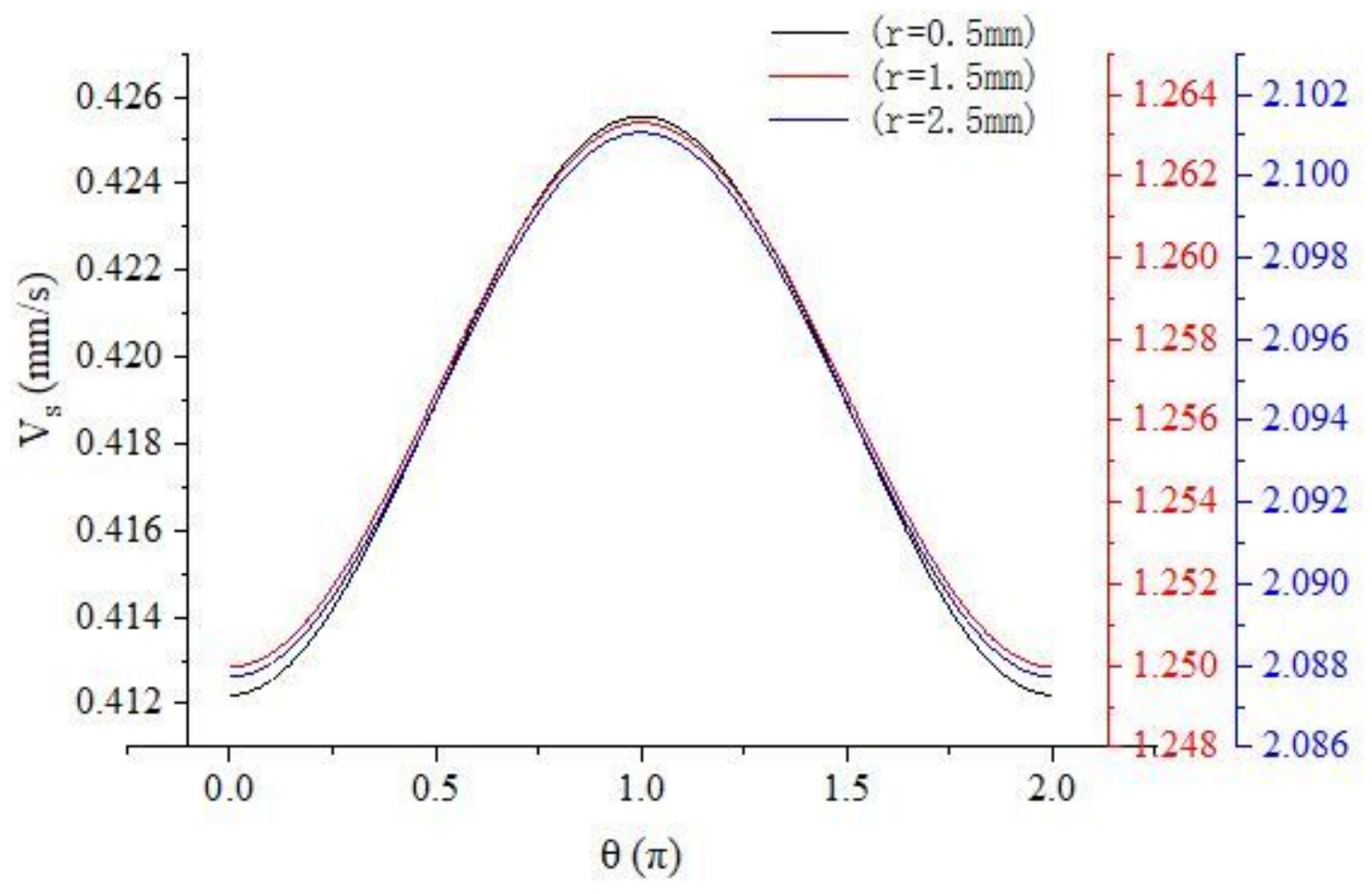

Figure 7

M1, M2, M3 speed curve 


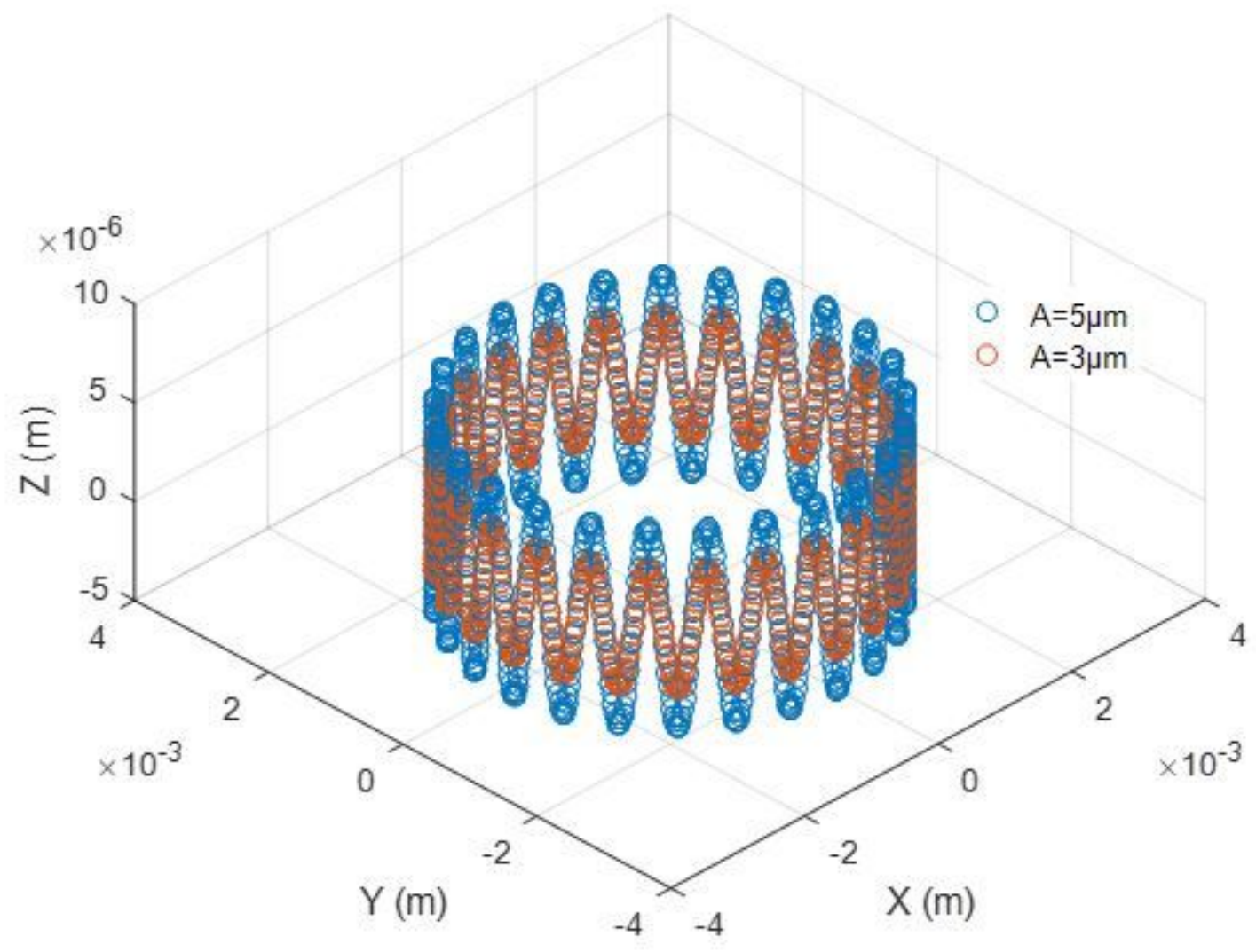

Figure 8

Free abrasive particle motion trajectory with different amplitude 


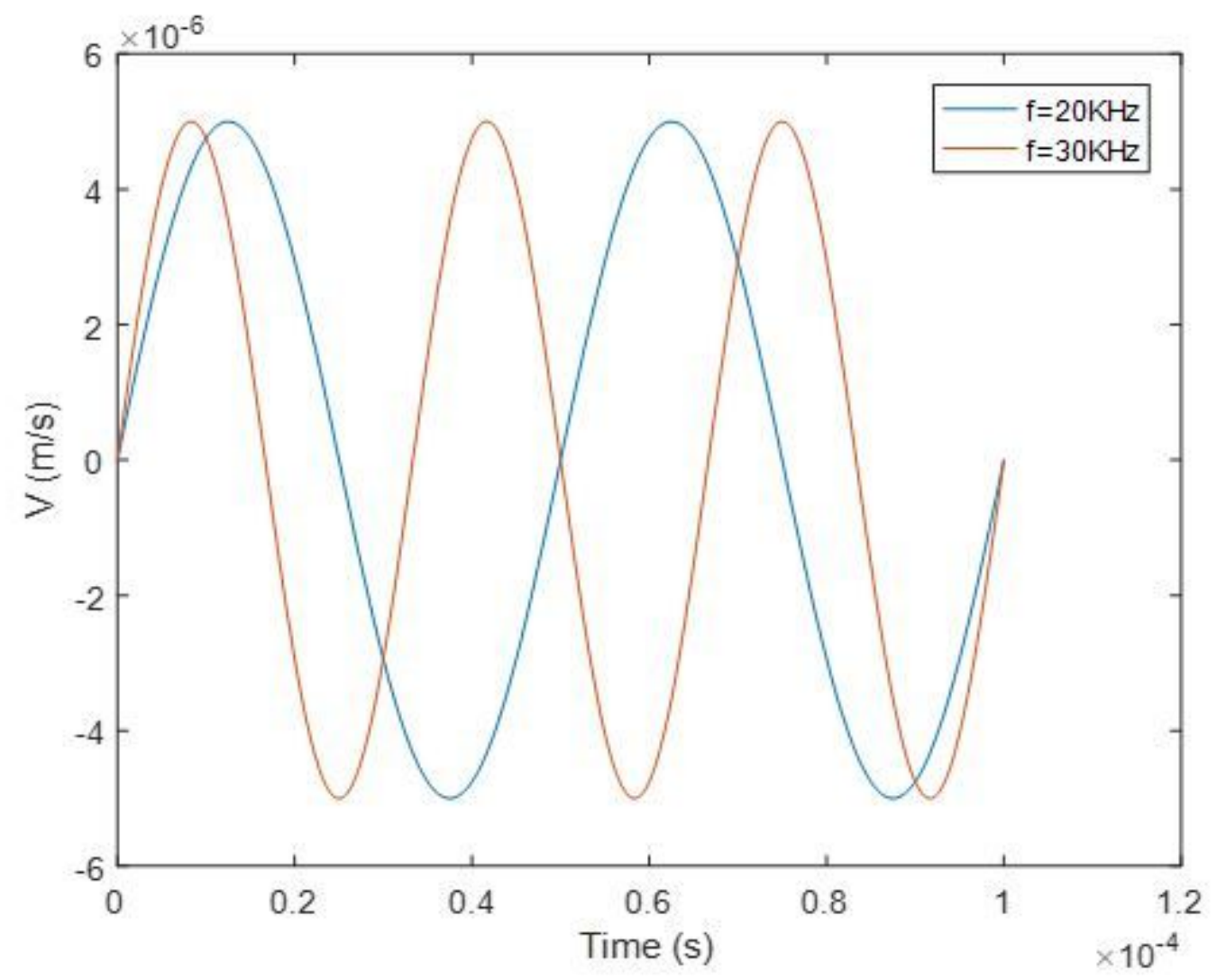

Figure 9

Free abrasive particle velocity curves at different frequencies 


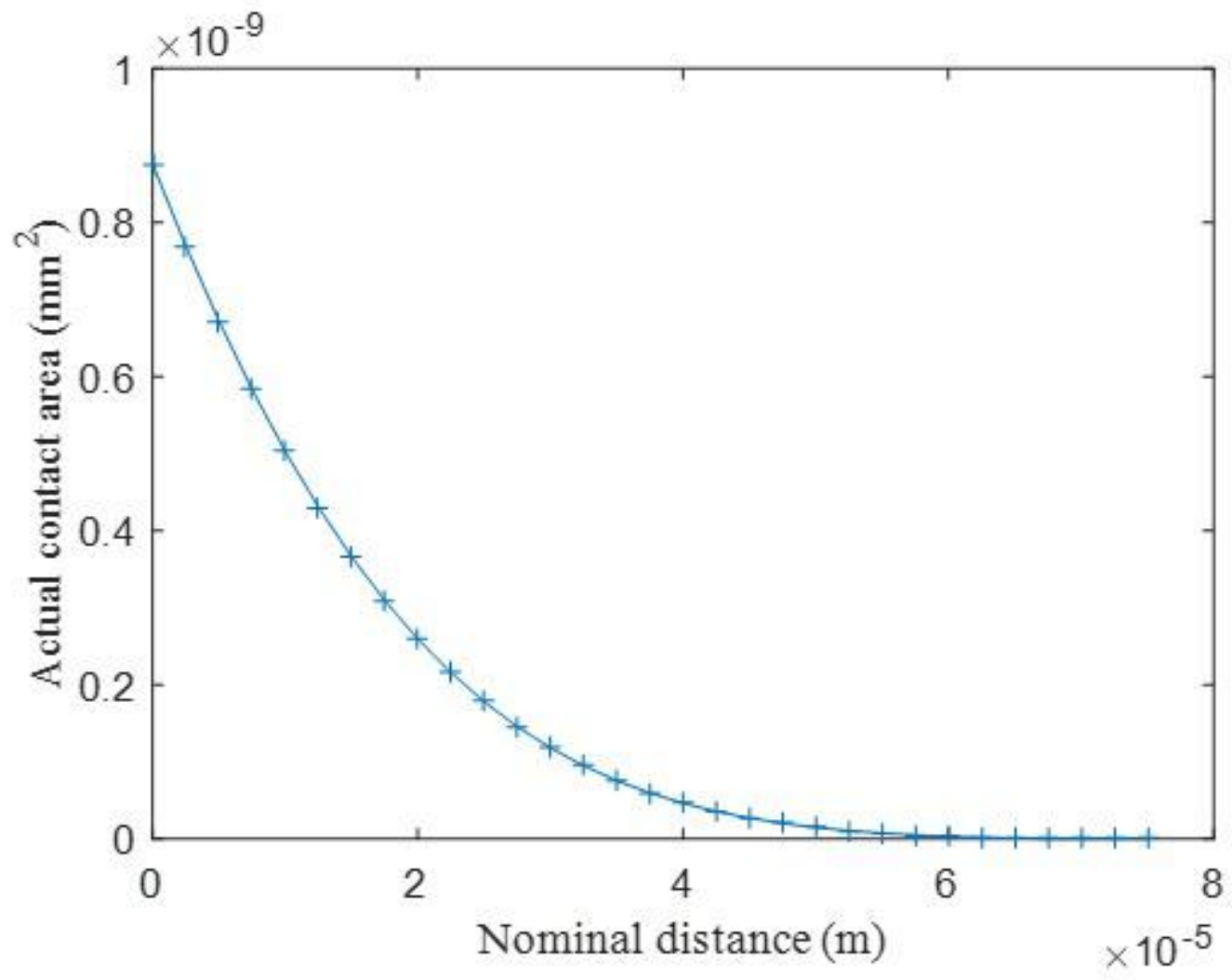

Figure 10

Relationship curve between nominal distance and actual contact area 


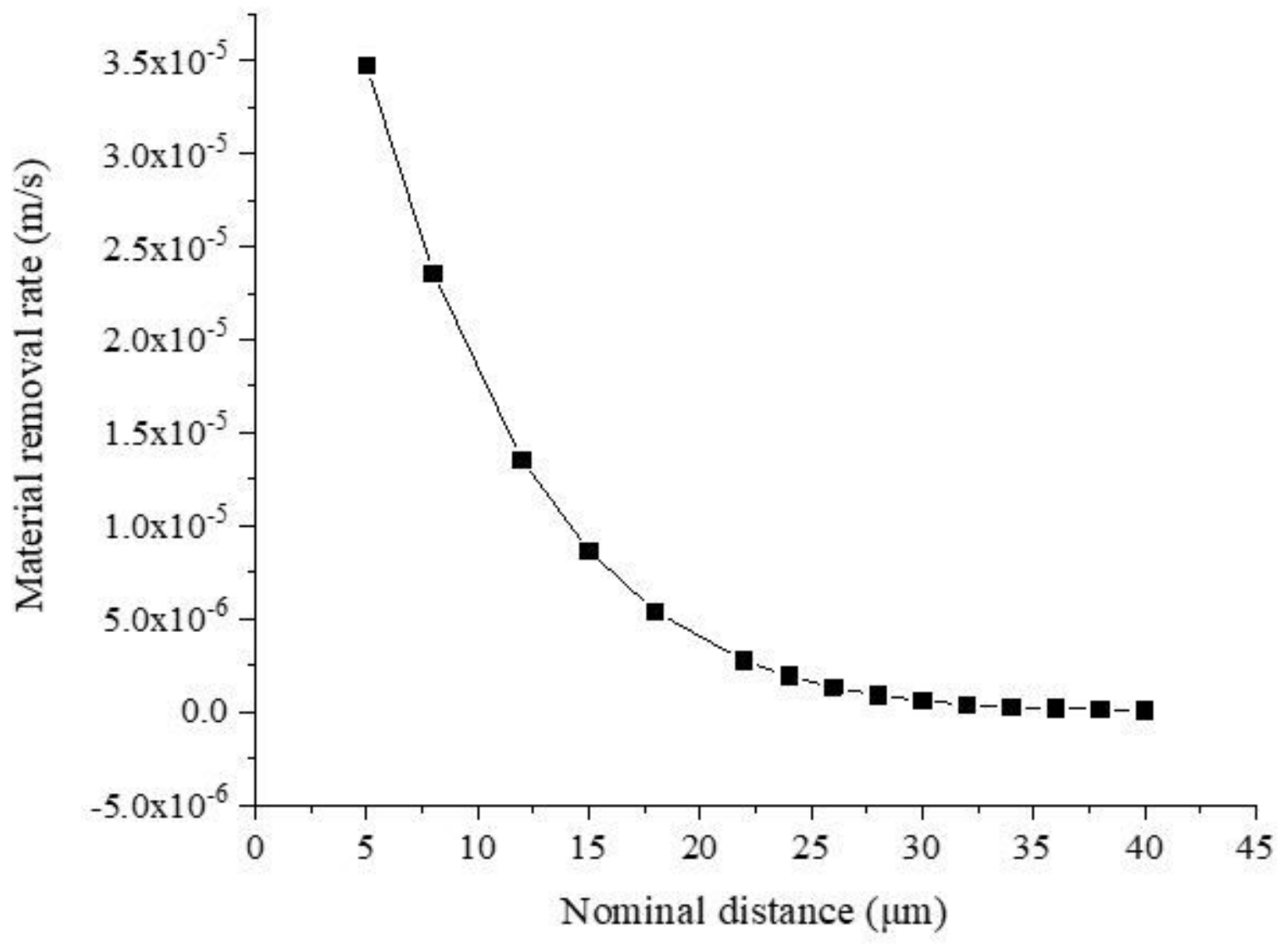

Figure 11

Effect of nominal distance on material removal rate 


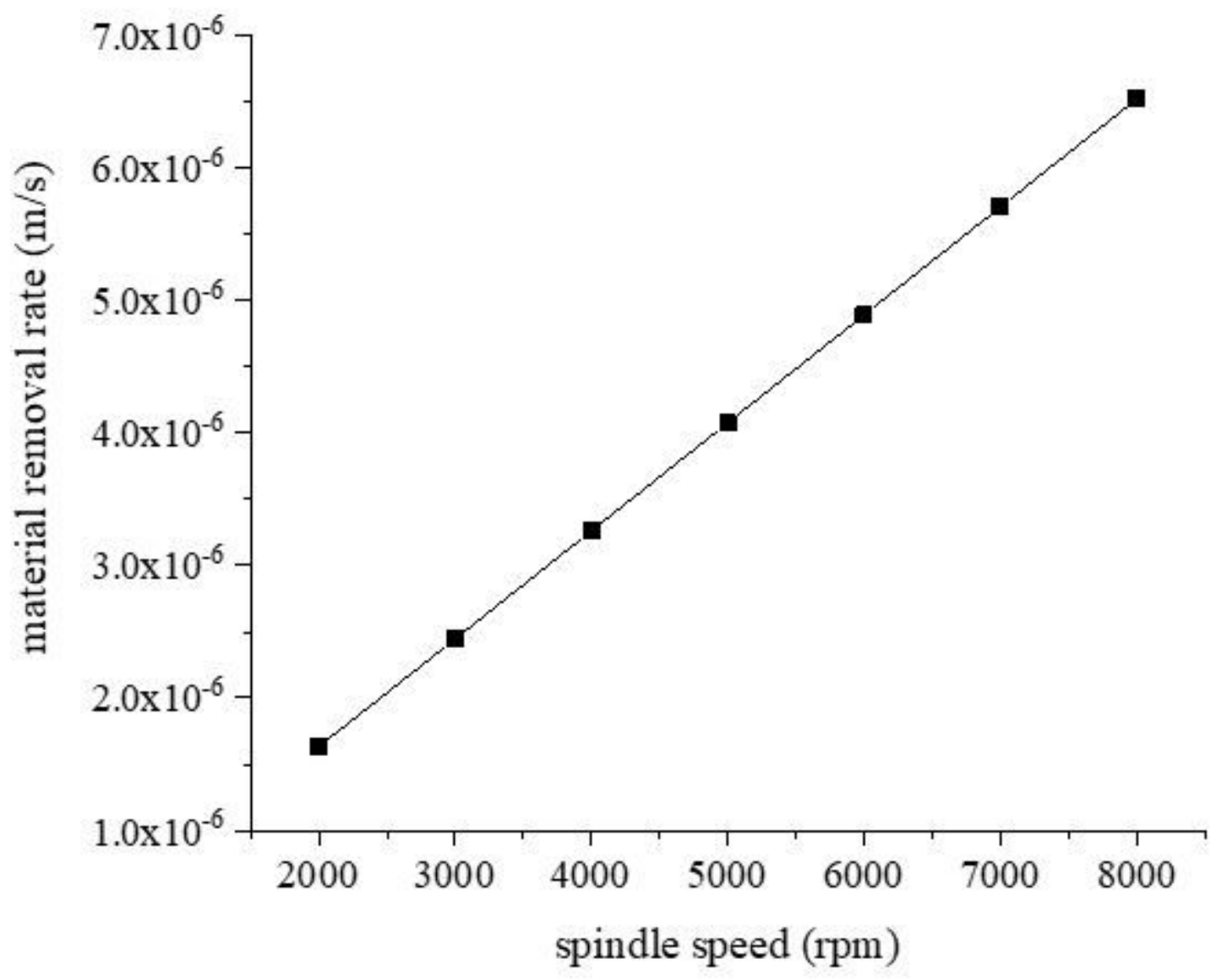

Figure 12

Effect of spindle speed on material removal rate 


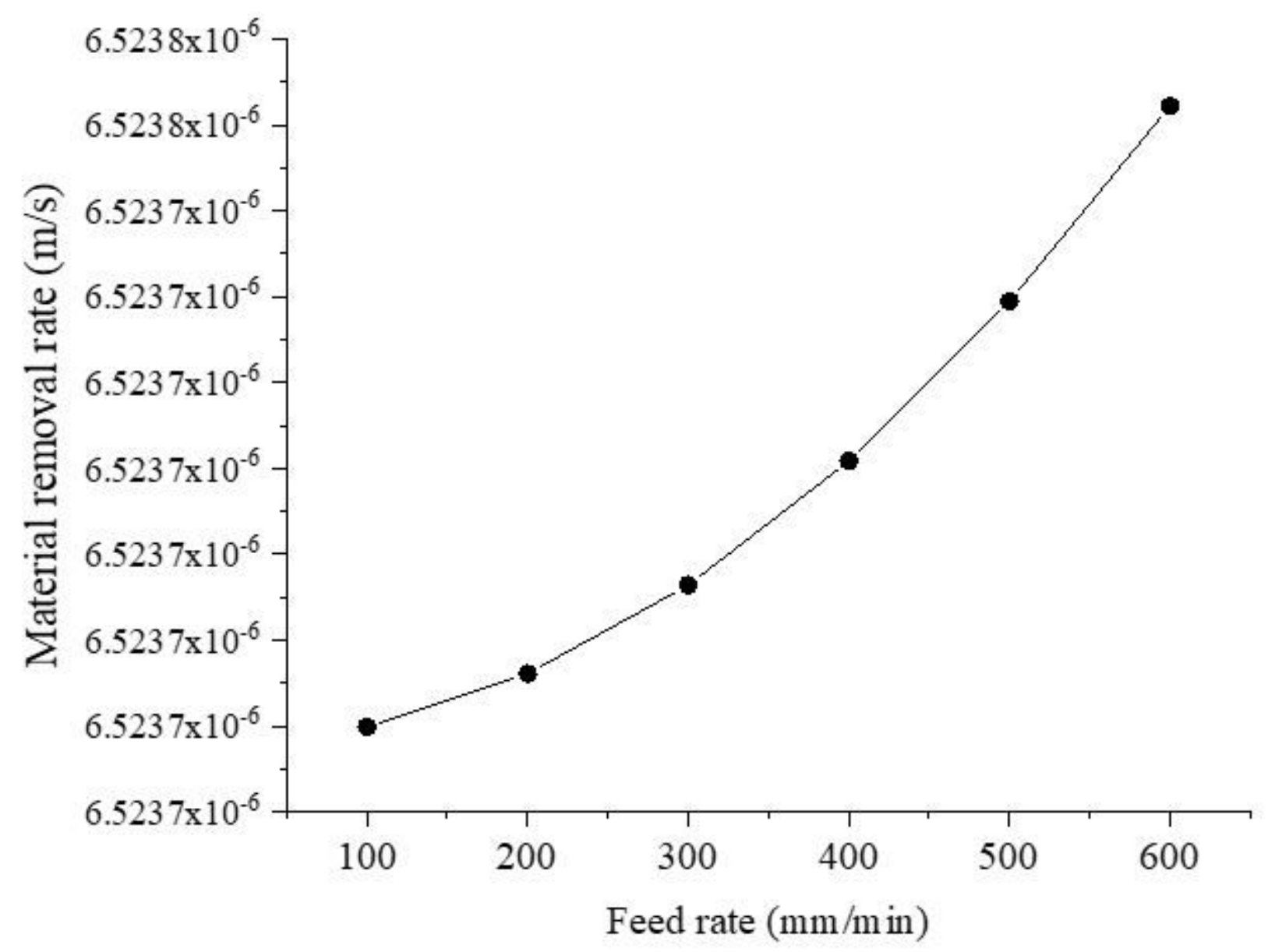

Figure 13

Effect of feed speed on material removal rate 


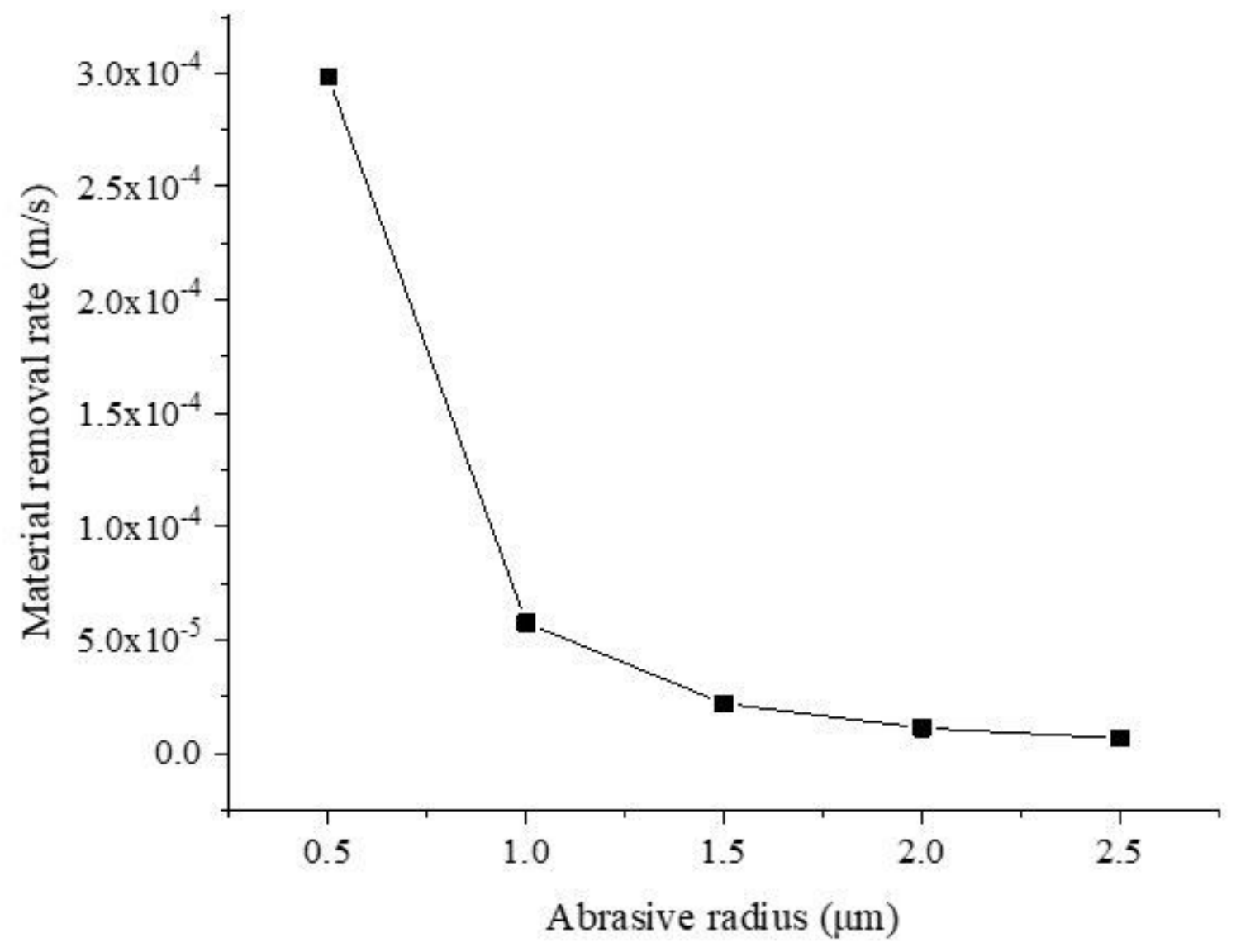

Figure 14

Effect of abrasive particle radius on material removal rate 


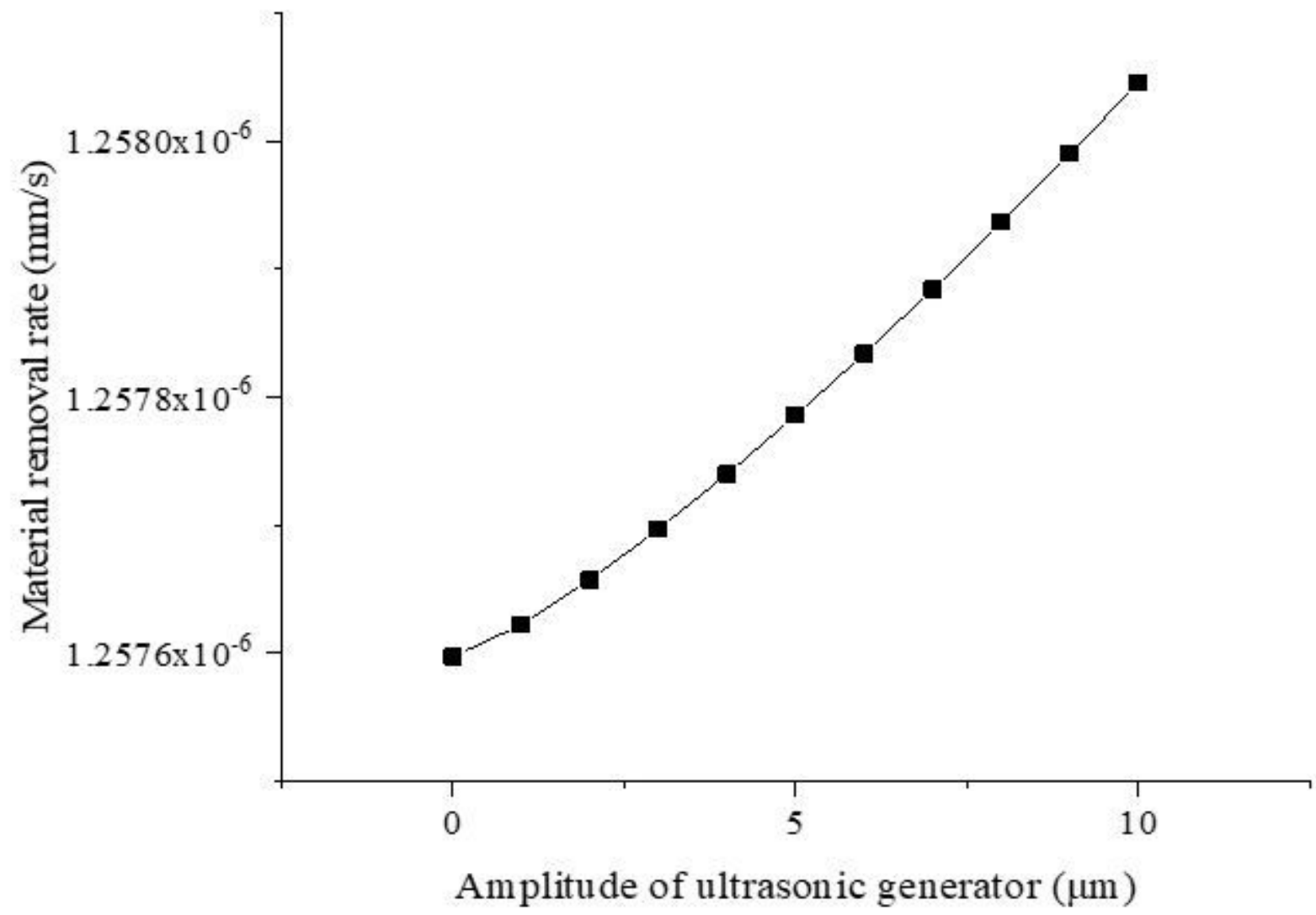

Figure 15

Effect of amplitude of ultrasonic generator on material removal rate 


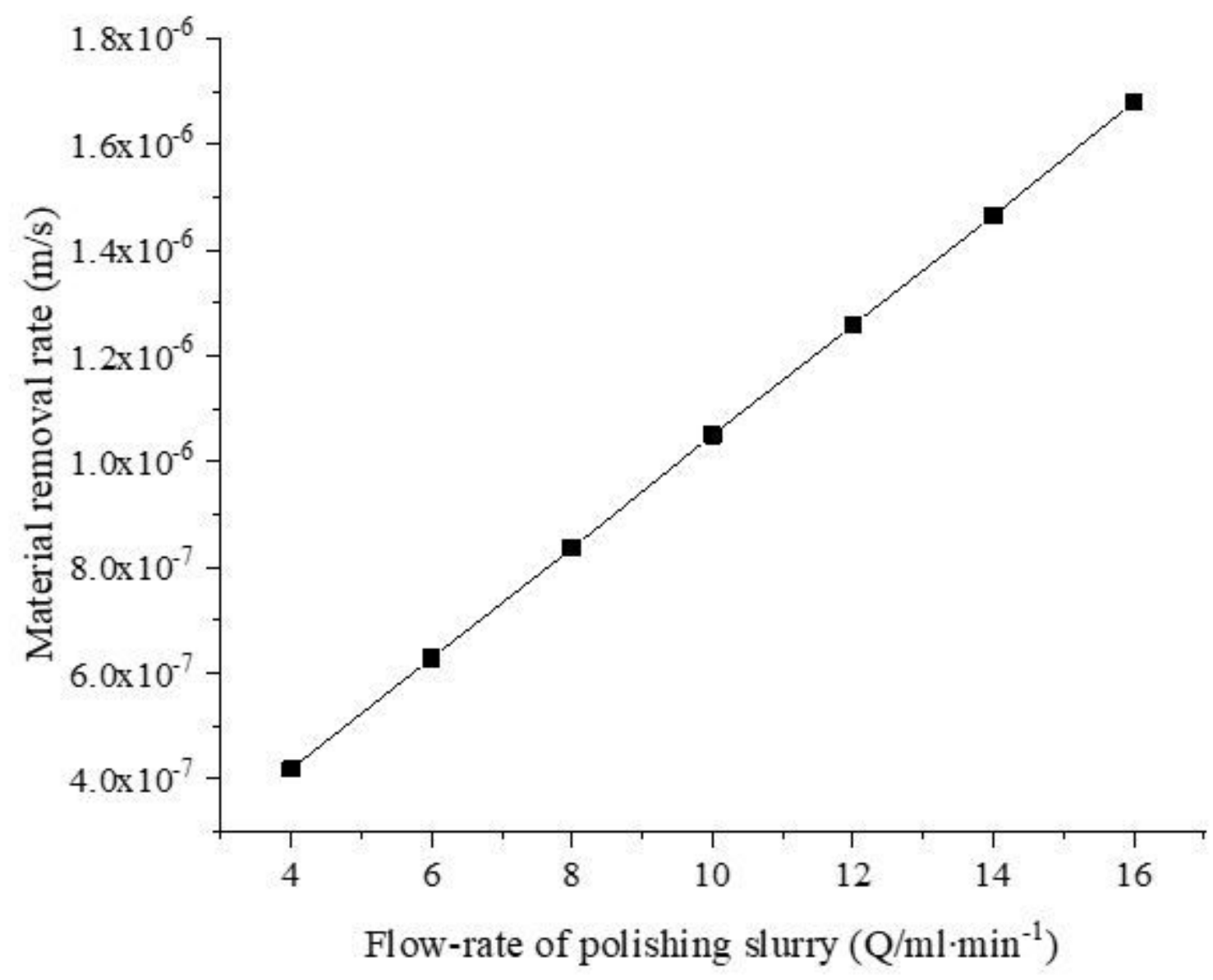

Figure 16

Effect of flow-rate of polishing slurry on material removal rate 